\title{
SYNTHESIS, CHARACTERIZATION AND DENSITY FUNCTIONAL THEORY OF COPPER(II) COMPLEX AND COBALT(II) COORDINATION POLYMER FOR DETECTION OF NITROAROMATIC EXPLOSIVES
}

Adedibu C. Tella $\mathrm{a}^{\mathrm{a}}$, Victoria T. Olayemi ${ }^{\mathrm{a}, \mathrm{b}}$, Folahan A. Adekola ${ }^{\mathrm{a}}$, Adetola C. Oladipo ${ }^{\mathrm{a}, \mathrm{c}}$, Vincent O. Adimula ${ }^{\mathrm{a}}$, Joseph O.Ogar ${ }^{\mathrm{e}}$, Eric C. Hosten ${ }^{\mathrm{d}}$, Adeniyi S. Ogunlaja ${ }^{\mathrm{d}}$ Stephen P. Argent ${ }^{\mathrm{e}}$ and Robert Mokaya ${ }^{\mathrm{e}}$

${ }^{a}$ Department of Chemistry, University of Ilorin, P.M. B 1515, Ilorin, Kwara State, Nigeria. Email:actella@yahoo.co.ukPhone:+2348035019197

${ }^{b}$ Department of Chemistry, College of Pure and Applied Sciences, Kwara State University, P.M. B 1530, Malete, Nigeria.

${ }^{c}$ Department of Physical Sciences, Landmark University, Omu-Aran, Kwara State, Nigeria

${ }^{d}$ Department of Chemistry, Nelson Mandela University, PO Box 77000, Port Elizabeth, 6031, South Africa.

${ }^{e}$ School of Chemistry, University of Nottingham, NG7 2RD, University Park, Nottingham, United Kingdom.

\begin{abstract}
In recent years there has been a significant interest to design luminescent materials to detect explosives with a great degree of selectivity, sensitivity, and fast response time. Two new luminescent compounds, $\left[\mathrm{Cu}(\right.$ Biphen $\left.)(\mathrm{Meim})\left(\mathrm{H}_{2} \mathrm{O}\right)\right] \mathbf{1}$ and $\left[\mathrm{Co}(\mathrm{BDC})(\mathrm{Meim})_{2}\right]_{\mathrm{n}} 2$ (where HBiphen = biphenyl-4-carboxylic acid, $\mathrm{H}_{2} \mathrm{BDC}=1$,4-benzenedicarboxylic acid and Meim = 1-methylimidazole) were synthesized under solvothermal and reflux conditions. The compounds were characterized by elemental analysis, FT-IR, thermogravimetric analysis, and electronic spectroscopy. Single Crystal X-ray Diffraction (SC-XRD) was used to determine their crystal structures. 1 crystallizes in the monoclinic space group $I 2 / a$, and the geometry around the metal center is square pyramidal connected by two $(\mu-\mathrm{N})_{2}$ of Meim and two $(\mu-\mathrm{O})_{2}$ of Biphen and a coordinated water molecule. 2 exhibits tetrahedral geometry connected by two $(\mu-\mathrm{N})_{2}$ of Meim and two $(\mu-\mathrm{O})_{2}$ halves of BDC in the triclinic space group P-1. Photophysical properties of the solid-state complexes were analyzed using fluorescence spectroscopy. 1 displayed high emissions at $430 \mathrm{~nm}\left(\lambda_{\mathrm{ex}}=264 \mathrm{~nm}\right)$ and 2 at $384 \mathrm{~nm}\left(\lambda_{\mathrm{ex}}=265 \mathrm{~nm}\right)$ which could be assigned to ligand to metal charge transfer (LMCT) due to the ligand's extended $\pi$ conjugation. Compounds $\mathbf{1}$ and $\mathbf{2}$ display selective nitroaromatic quenching response over other organic molecules having detection limits ranging between $1.66 \mathrm{ppm}$ and $13.07 \mathrm{ppm}$, respectively. Density Functional Theory (DFT) revealed that potential interactions leading to the formation of adducts result from the transfer of electrons by hydrogen bonding and $\pi-\pi$ stacking. Compound $\mathbf{2}$ was found to have greater ability to quench nitro analytes.
\end{abstract}

Keywords Coordination Polymers, Fluorescence, Nitroaromatics, Solvothermal, Quenching

\section{Introduction}


Coordination polymers (CPs) are a class of compounds constructed from metal ions bonded to organic ligands to form 1D, 2D and 3D structures. The structural properties of the compounds are explored by considering the functionality of the ligand and the geometry of the metal via crystal engineering leading to self-assembly of inorganic metal nodes and organic moieties [1]. Coordination polymers are of great interest owing to their promising applications in gas adsorption, catalysis, sensors, and drug delivery. The detection of nitro compounds has been of great concern in the past two decades due to its significance in global security and environmental protection [2]. While several methods for detecting nitro compounds have been developed, these methods of identification are restricted by equipment requirements and cost [3]. Recently, some researchers have reported the quenching of luminescence intensities of coordination polymers in the presence of nitro aromatic molecules [4]. Tehrani et al [5] investigated two novel sensing probes of metal coordination polymer for the sensing of nitro compounds. These two MOFs were suspended in a solution of different nitro compounds for sensing. The quenching efficiency of the MOFs for nitro-containing compounds revealed that 2,4,6-trinitrotoluene (TNT) has the highest quenching percentage as compared to the other nitroaromatic compounds, and that possible interactions between the MOFs and the nitro analytes arise from hydrogen bonds from the Urea groups in the MOF cavity and $\pi-$ stacking interactions. It was also observed that these interactions, and the orientation of the urea group within the pores of the MOFs, are vital for the sensing of nitro compounds. The luminescent MOFs can be designed for use in explosive detection in such a way that there will be a direct target between the framework and the guest resulting in guest-induced interactions. $\mathrm{Bu}$ et al, [6] also used another 3D MOF to examine the sensing ability of electron-withdrawing nitroaromatic explosives in solution or vapour. The electron rich ligand of the coordination polymer was advantageous to its sensitivity. The results showed that the limit of detection (LOD) of nitrobenzene was very low $(0.135 \mathrm{ppm})$ and its emission intensity was drastically 
quenched. Recently, Li and co-workers designed three multidimensional luminescent $\mathrm{Cu}(\mathrm{II})$ coordination polymers for selective detection of acetylacetone, benzaldehyde and $\mathrm{Cr}_{2} \mathrm{O}_{7}{ }^{2-}[7]$. The quenching effect was ascribed to electron-transfer transitions of the analytes decreasing the energy transfer between the $\pi$ and $\pi^{*}$ orbitals of the bis(benzimidazole) N-ligands. Yang et al [8] reported the dual-responsive detection of acetylacetone and $\mathrm{Cr}_{2} \mathrm{O}_{7}^{2-}$ in aqueous solution using a water-stable Cd(II) MOF. The quenching effect was attributed to resonance energy transfer from the excited MOF to the acetylacetone and $\mathrm{Cr}_{2} \mathrm{O}_{7}{ }^{2-}$. This was clearly observed from the large overlaps with the excitation band of the MOF. Following our studies on the synthesis and application of coordination polymers in environmental remediation $[9,10]$, luminescence [11] and chemical sensing [12], we report the synthesis of copper(II) complex and cobalt(II) coordination polymers assembled from carboxylate and 1-methylimidazole ligands for the detection of nitroaromatic explosives.

\section{Experimental}

\subsection{Materials and methods}

All reagents and chemicals are of analytical grade and were used as received without further purification. 1,4-Benzenedicarboxylic acid, Biphenyl-4-carboxylic acid, 1-methylimidazole (s.g. 1.03) were purchased from Sigma Aldrich, Germany. $\mathrm{CoCl}_{2} \cdot 2 \mathrm{H}_{2} \mathrm{O}$ and $\mathrm{CuSO}_{4} \cdot 5 \mathrm{H}_{2} \mathrm{O}$ were supplied by Alfa Aesar, UK. Solvents: Ethanol (98.8\%), N,N-Dimethyl formamide (99.0\%) were obtained from Central Drug House (P) Ltd New Delhi India.

\subsection{Instrumentation and characterization}

The samples were characterized by elemental analysis using an Exeter Analytical CE-440 Elemental Analyser. The infrared spectra were recorded using a Bruker Alpha diamond module FT-IR spectrometer with attenuated total reflectance (ATR) attachment for solid samples. Powder X-ray diffraction (PXRD) patterns were measured on a PANalytical X'Pert PRO 
diffractometer with a $\mathrm{Cu}-\mathrm{K} \alpha$ light source $(40 \mathrm{kV}, 40 \mathrm{~mA})$ with a step size of $0.02^{\circ}$ and a $50 \mathrm{~s}$ time step. UV-Vis absorption spectra were measured in the solid-state in the range 200 to $800 \mathrm{~nm}$ using an Agilent Cary Spectrophotometer with a slit width of $2 \mathrm{~nm}$. The fluorescence emission spectra were recorded on an Agilent Cary Eclipse Spectrophotometer set at $2 \mathrm{~nm}$ slit width for both the excitation and emission. TGA was performed using an SDT-Q600 TA instrument. The samples were heated in air with a heating rate of $10{ }^{\circ} \mathrm{C} \mathrm{min}^{-1}$ and the scan was recorded within the temperature range of $30-600{ }^{\circ} \mathrm{C}$.

\subsection{Synthesis of the compounds}

\section{$\mathrm{Cu}$ (Biphen)(Meim) $\left(\mathrm{H}_{2} \mathrm{O}\right) \mathbf{I}$}

1 was synthesized by dissolving $0.249 \mathrm{~g}$ of $\mathrm{CuSO}_{4} .5 \mathrm{H}_{2} \mathrm{O}(1 \mathrm{mmol})$ in $10 \mathrm{~mL}$ distilled water and was mixed carefully with $0.198 \mathrm{~g}(1 \mathrm{mmol})$ of Biphenyl-4-carboxylic acid previously dissolved in $10 \mathrm{~mL}$ ethanol solution. $0.1 \mathrm{~mL}$ of 1 -methylimidazole in $5 \mathrm{~mL}$ ethanol was added while stirring gently. The blue suspension formed was heated at $80{ }^{\circ} \mathrm{C}$ in the oven for $4 \mathrm{~h}$ under atmospheric condition. Blue spherical crystals were harvested by filtration after $24 \mathrm{~h}$. Yield = $83 \%$, M.P $=228{ }^{\circ} \mathrm{C}, \mathrm{C}_{34} \mathrm{H}_{32} \mathrm{~N}_{4} \mathrm{O}_{5} \mathrm{Cu}\left(640.19\right.$ gmol $\left.^{-1}\right)$. Anal. found: $\mathrm{C} ; 63.74, \mathrm{H} ; 4.93, \mathrm{~N} ; 8.78 \%$. Calcd: C; 63.79, H; 5.04, N; 8.75\%. IR (ATR cm cm $^{-1}$ 3373, 3124, 1600, 1241, 1375, 652, 473.<smiles>Cn1ccnc1</smiles><smiles>CCOCCOC(C)O</smiles><smiles>CN1C=C[I-]C1</smiles><smiles></smiles>

Scheme 1: Reaction pathway of $\left[\mathrm{Cu}(\right.$ Biphen $\left.)(\mathrm{Meim})\left(\mathrm{H}_{2} \mathrm{O}\right)\right]$

$\left[\mathrm{Co}(\mathrm{BDC})(\mathrm{Meim})_{2}\right]_{n} 2$ 
2 was synthesised by dissolving $0.237 \mathrm{~g}(1 \mathrm{mmol})$ of $\mathrm{CoCl}_{2} \cdot 2 \mathrm{H}_{2} \mathrm{O}$ in $10 \mathrm{~mL}$ distilled water and carefully layering it over $0.166 \mathrm{~g}(1 \mathrm{mmol})$ of 1,4-benzenedicarboxylic acid (BDC) in $10 \mathrm{~mL}$ $N, N$-dimethylformamide in a $100 \mathrm{~mL}$ Pyrex beaker. $0.08 \mathrm{~mL}(1 \mathrm{mmol})$ of 1-methylimidazole

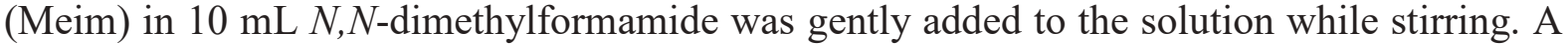
clear purple-coloured solution was formed and was refluxed at $120{ }^{\circ} \mathrm{C}$ for $2 \mathrm{~h}$. Purple crystals of 2 were harvested by filtration after 3 days with a yield of $79 \%$. M.P $=373{ }^{\circ} \mathrm{C}, \mathrm{C}_{16} \mathrm{H}_{16} \mathrm{~N}_{4} \mathrm{O}_{4} \mathrm{Co}$ (387.26 gmol $\left.^{-1}\right)$. Anal. found: C; 49.52, H; 3.99, N; 14.24\%. Calcd: C; 49.50, H; 4.41, N; 14.43\%. IR (ATR cm $\left.\mathrm{cm}^{-1}\right): 3123,1580,1235,1360,552,495$.

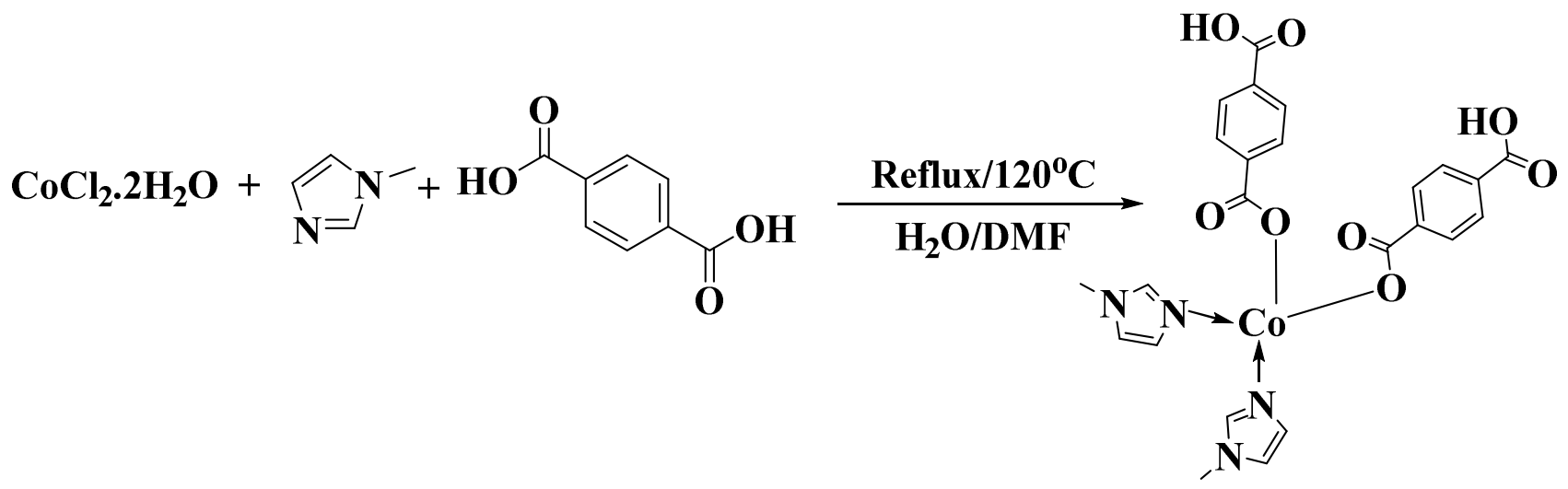

Scheme 2: Reaction pathway of $\left[\mathrm{Co}(\mathrm{BDC})(\mathrm{Meim})_{2}\right]_{\mathrm{n}}$

\subsection{Fluorescence Experiment}

The method described by Wang et al; 2013 was modified and adopted for the fluorescence experiment [13]. $3 \mathrm{mg}$ of finely ground samples were dispersed in $1 \mathrm{mM}$ of three different aromatic nitro compounds (nitrobenzene, 4-nitroaniline and 4-nitrophenol) and then ultrasonicated for $30 \mathrm{~min}$. to form stable suspensions which was allowed to age for $24 \mathrm{~h}$ before fluorescence studies. To examine the selectivity of the compounds (CPs) towards the nitro analytes, the compounds were used to probe other organic molecules (ethanol, DMF, methanol, benzene).

\subsection{Computational Details}


Single crystal X-ray diffraction structures of $\left[\mathrm{Cu}(\text { Biphen)(Meim })_{2}\left(\mathrm{H}_{2} \mathrm{O}\right)\right]$ and $\left[\mathrm{Co}(\mathrm{BDC})(\mathrm{Meim})_{2}\right]_{\mathrm{n}}$ were used for geometry optimization. Highest Occupied Molecular Orbital (HOMO) and Lowest Unoccupied Molecular Orbital (LUMO) energies were generated with the Gaussian09 quantum chemistry package [14] at the DFT (Density Functional Theory) B3LYP/6-311++G**(d,p) level $[15,16]$. Optimized molecules were obtained with the Avogadro and Chemcraft visualization program.

\subsection{X-ray Crystallography}

Single crystal X-ray data for $\mathbf{1}$ was collected at $200 \mathrm{~K}$ on a Bruker Kappa Apex II diffractometer, and 2 at $120 \mathrm{~K}$ on a GV1000, Atlas S2 diffractometer. The Olex2 suite was used as a graphic user interface (GUI) and as imaging software [17]. The structures were solved with the ShelXT [18] structure solution program using Intrinsic Phasing and refined with the ShelXL [19] refinement package using Least Squares minimisation. All non-hydrogen atoms were refined with anisotropic displacement parameters and images were prepared via Mercury 4.1.0.

Table 1a: Crystal data and structure Refinement Details for 1 and 2

\begin{tabular}{lll}
\hline Details & $\mathbf{1}$ & $\mathbf{2}$ \\
\hline Empirical formula & $\mathrm{C}_{34} \mathrm{H}_{32} \mathrm{CuN}_{4} \mathrm{O}_{5}$ & $\mathrm{C}_{16} \mathrm{H}_{16} \mathrm{CoN}_{4} \mathrm{O}_{4}$ \\
Formula weight & 640.19 & 387.26 \\
$\mathrm{~T}(\mathrm{~K})$ & 200 & 120 \\
Wavelength $(\AA)$ & 0.71073 & 1.542 \\
Crystal system & Monoclinic & Triclinic \\
Space group & $\mathrm{I} 2 / \mathrm{a}$ & $\mathrm{P}-1$ \\
Crystal size $(\mathrm{nm})$ & $0.23 \times 0.28 \times 0.38$ & $0.86 \times 0.34 \times 0.32$ \\
$\mathrm{a}(\AA)$ & $16.8401(9)$ & $7.5184(4)$ \\
$\mathrm{b}(\AA)$ & $6.0328(4)$ & $8.8257(4)$ \\
\hline
\end{tabular}




\begin{tabular}{lll}
\hline $\mathrm{c}(\AA)$ & $30.0546(16)$ & $13.1889(6)$ \\
$\alpha\left(^{\circ}\right)$ & 90 & $81.377(4)$ \\
$\beta\left(^{\circ}\right)$ & $101.509(3)$ & $77.441(4)$ \\
$\gamma\left({ }^{\circ}\right)$ & 90 & $72.717(4)$ \\
$\mathrm{V}\left(\AA^{3}\right)$ & $2991.9(3)$ & $812.28(7)$ \\
$\mathrm{Z}$ & 4 & 2 \\
$\rho_{\text {calc}\left(\mathrm{g} / \mathrm{cm}^{3}\right)}$ & 1.421 & 1.583 \\
$\mathrm{~F}(000)$ & 1332 & 398 \\
$2 \Theta$ range for data collection $\left(^{\circ}\right)$ & $4.938-56.71$ & $6.894-145.88$ \\
Radiation type & $\mathrm{MoK \alpha}$ & $\mathrm{CuK \alpha}$ \\
Reflections collected & 3718 & 5599 \\
$\mathrm{R}$ indices R1/wR2 & $0.0289,0.0835$ & $0.0414,0.1094$ \\
Largest peak $\left(\mathrm{e} \mathrm{A}{ }^{3}\right)$ & 0.49 & 0.74 \\
Deepest hole $\left(\mathrm{e} \mathrm{A}{ }^{3}\right)$ & -0.44 & -0.85 \\
\hline
\end{tabular}

\section{Results and discussion}

\subsection{Structural description}

The molecular structure of $\mathbf{1}$ showing atom numbering is given in Fig. 1a. Detailed crystallographic data and structure refinement parameters are summarized in Table 1a, while selected bond lengths and bond angles are presented in Table 1b. 1 crystallizes in the monoclinic crystal system $(a=16.840, b=6.032, c=30.054)$ with space group I2/a. The square pyramidal $\mathrm{Cu}(\mathrm{II})$ ion is coordinated by two $(\mu-\mathrm{N})_{2}$ of Meim and two $(\mu-\mathrm{O})_{2}$ of Biphen symmetrical around a 2-fold rotational axis in the basal plane, with the apical position occupied by a coordinated water molecule. The complex revealed a slightly distorted square-pyramidal geometry with a distortion parameter $\tau$ of $0.19[20,21]$. The Biphen is completely deprotonated and the coordination mode of the carboxylic acid groups around the $\mathrm{Cu}(\mathrm{II})$ ion is monodentate. The Cu1-O21 distances is 1.957(9) $\AA$ (Table 1b) which compares favourably with the range 
1.930-1.990 A [22] usually observed for copper complexes. The bond length of the two Cu1N11 bonds is $1.992(12) \AA$ which agrees favourably with the reported range of 1.974-2.008 $\AA$ [23]. The bond angle between the imidazoyl nitrogen (N11), copper and oxygen of carboxylates $(\mathrm{N}-\mathrm{Cu} 1-\mathrm{O})$ is in the range of $87.9(5)-97.5(4)^{\circ}$. The $\mathrm{O}-\mathrm{H} \cdots \mathrm{O}$ type of intermolecular hydrogen bonds exist between the bound water molecule and $\mathrm{O} 22$ of the carboxylate group linking adjacent molecules along the b-axis. The bond distances and angles for the hydrogen bonding interaction are $\mathrm{O} 3-\mathrm{H} 3=0.88 \AA, \mathrm{H} 3 \cdots \mathrm{O} 22=2.754 \AA, \mathrm{O} 3-\mathrm{O} 22=1.88 \AA$ and $\mathrm{O} 3-\mathrm{H} 3 \cdots \mathrm{O} 22$ $=170^{\circ}$ (Fig.1b). The crystal packing is depicted in Fig. S1 consisting of layers mutually interacting by weak $\pi-\pi$ stacking via the imidazoyl ring, thereby stabilizing the crystal structure.

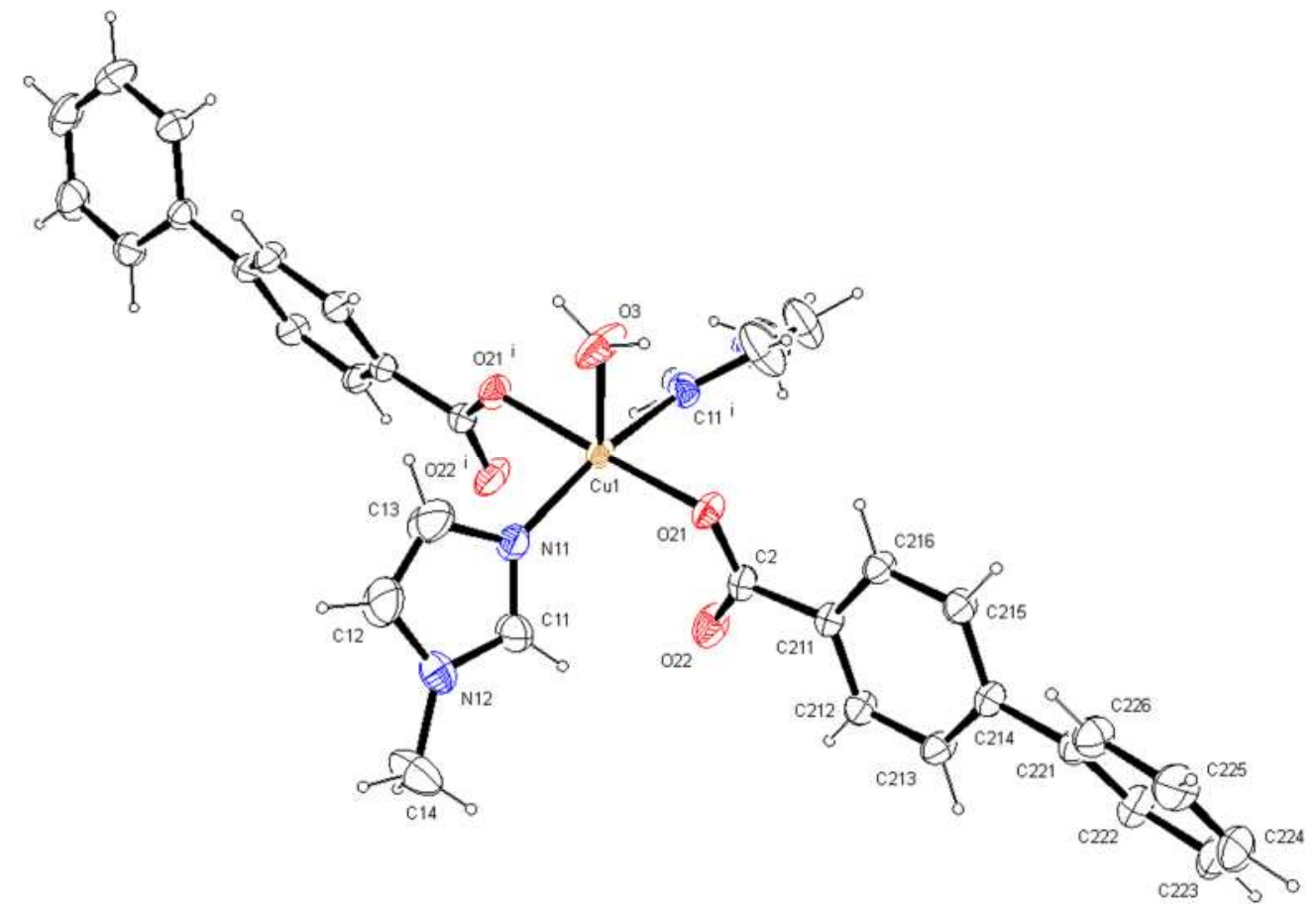

Fig. 1a: ORTEP view of $\left[\mathrm{Cu}(\right.$ Biphen $\left.)(\mathrm{Meim})\left(\mathrm{H}_{2} \mathrm{O}\right)\right](\mathbf{1})$ drawn at $50 \%$ ellipsoid. 


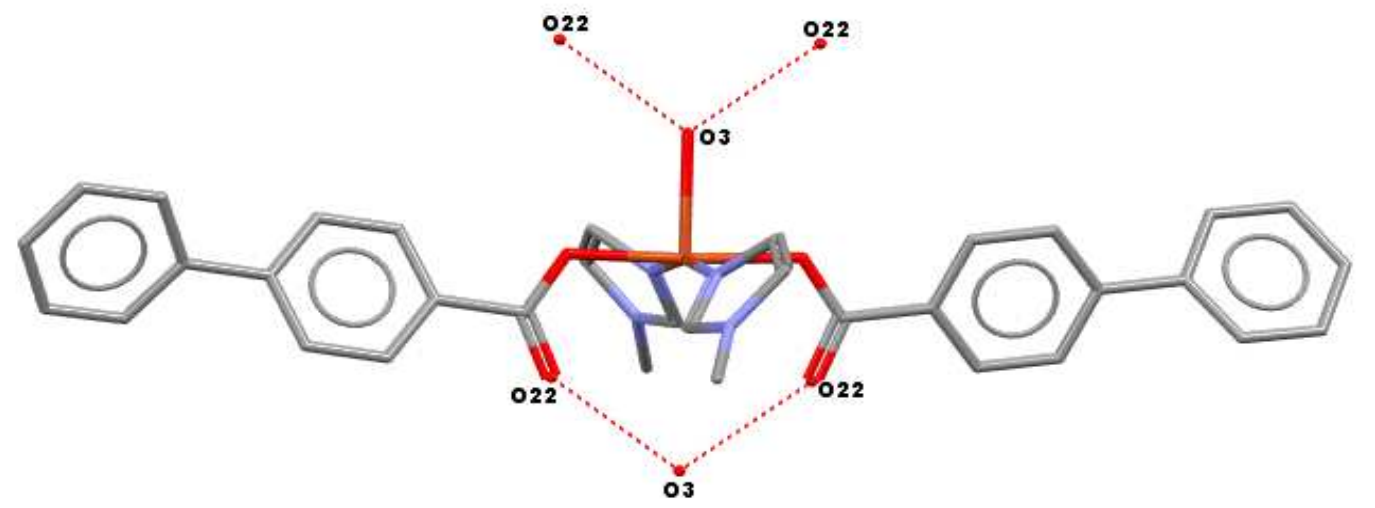

Fig. 1b: Hydrogen bonding interaction in $\left[\mathrm{Cu}(\right.$ Biphen $\left.)(\mathrm{Meim})\left(\mathrm{H}_{2} \mathrm{O}\right)\right](\mathbf{1})$

2 is a centrosymmetric entity that crystallizes as a four-coordinate mononuclear polymer with a tetrahedral geometry (distortion parameter $\tau=0.81$ ). The Co(II) ion is surrounded by two Meim molecule and half a molecule of BDC ligand. The ORTEP diagram with atom numbering is shown in Fig. 2a. The average bond length of Co1-O is $2.001 \AA$ while that of Co1-N is 2.035 $\AA$ and are within the reported average bond lengths of Co-O and Co-N [24]. The bond angles O-Co1-N range from $106.0(8)^{\circ}$ to $123.8(7)^{\circ}$, while that of O-Co1-O is $100.3^{\circ}$. These compare favourably with those reported in literature for $\mathrm{Co}(\mathrm{II})$ polymers [25]. Table 1a presents the selected interatomic bond lengths and bond angles. The completely deprotonated BDC ligand shows a monodentate coordination environment around the $\mathrm{Co}^{2+}$ ion, while the Meim adopts a cis-conformation. The Co(II) cations are bridged by BDC to form a $1 \mathrm{D}$ zigzag chain with the Meim ligands serving as pendant, as shown in Fig. 2b. The $\mathrm{C}-\mathrm{H} \cdots \pi$ interaction observed between the aromatic ring of $\mathrm{BDC}$ ligand and $\mathrm{CH}$ group of imidazole ring has a distance of $3.620 \AA$ as shown in Fig. S2. 


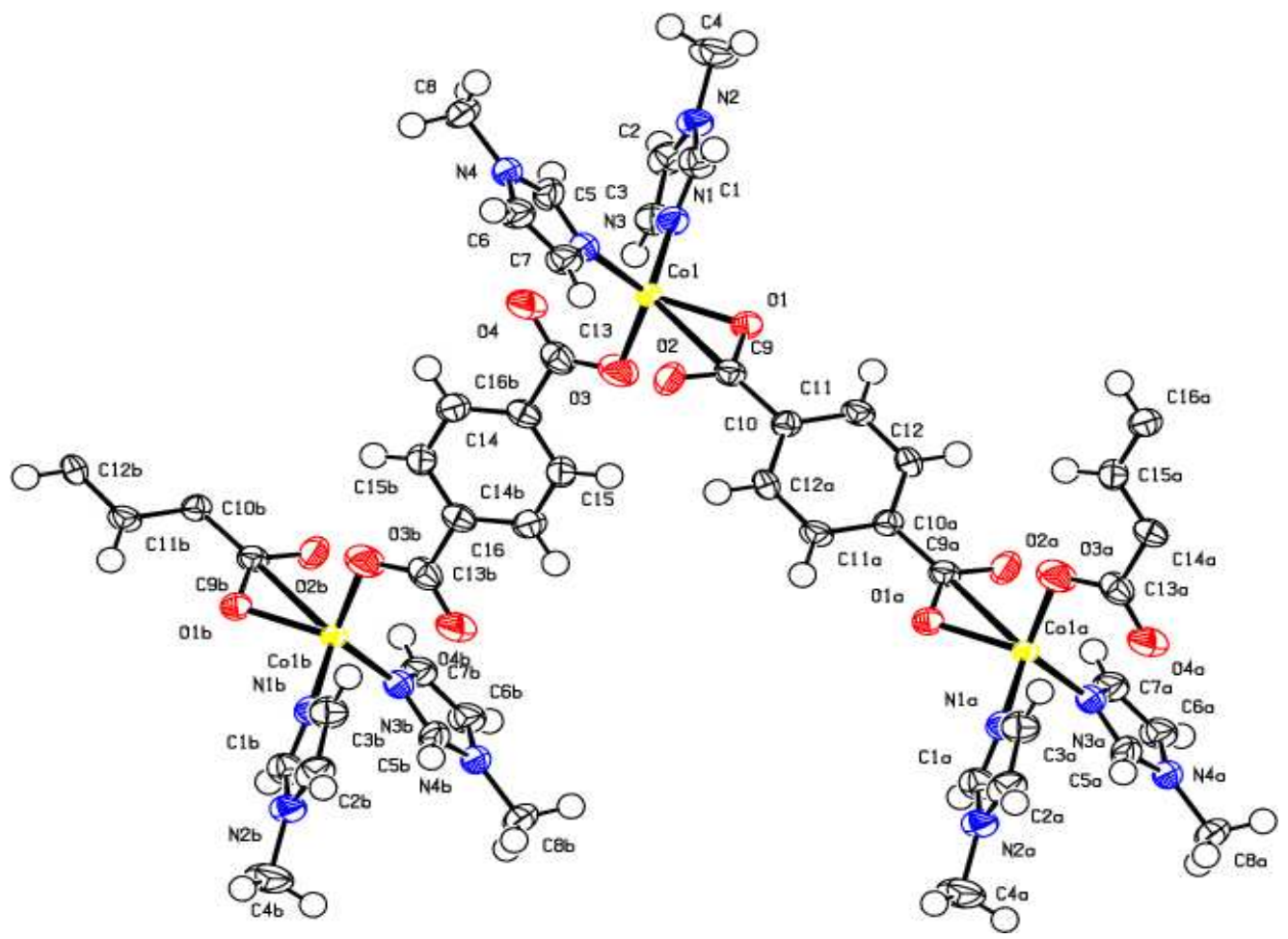

Fig. 2a: ORTEP view of $\left[\mathrm{Co}(\mathrm{BDC})(\mathrm{Meim})_{2}\right]_{\mathrm{n}}(2)$ drawn at $50 \%$ ellipsoid.

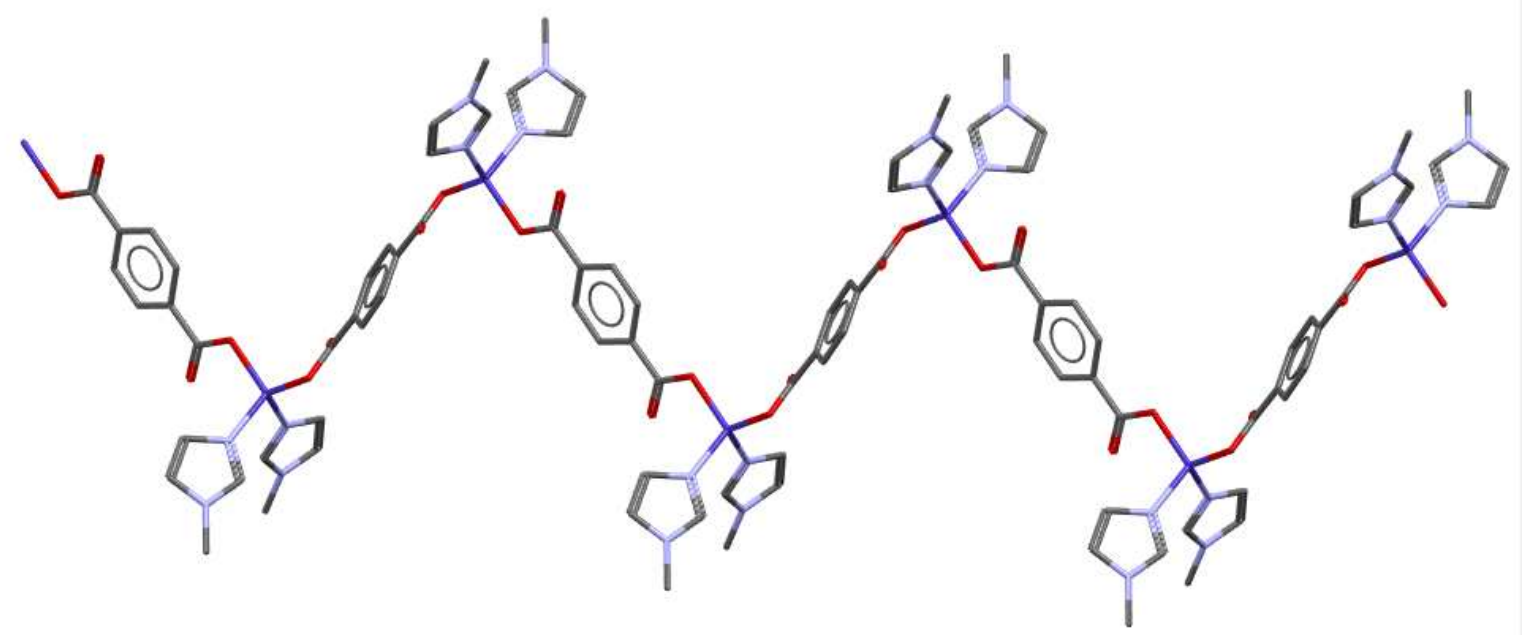

Fig. 2b: 1D zigzag chain of $\left[\mathrm{Co}(\mathrm{BDC})(\mathrm{Meim})_{2}\right]_{\mathrm{n}}(\mathbf{2})$ 
Table 1b: Observed and calculated interatomic bond lengths $(\AA)$ and bond angles $\left(^{\circ}\right)$ of the compounds

\begin{tabular}{|c|c|c|c|c|c|}
\hline \multicolumn{4}{|c|}{1} & \multicolumn{2}{|c|}{2} \\
\hline Parameters & exp. & calcd & Parameters & exp. & calcd \\
\hline Bond lengths & - & - & Bond lengths & - & - \\
\hline $\mathrm{Cu} 1-\mathrm{O} 3$ & $2.241(18)$ & 2.24243 & $\mathrm{Co} 1-\mathrm{O} 1$ & $1.999(15)$ & 1.99907 \\
\hline $\mathrm{Cu} 1-\mathrm{O} 21 \_\mathrm{a}$ & $1.957(9)$ & 1.95121 & $\mathrm{Co} 1-\mathrm{O} 3$ & $1.975(17)$ & 1.97483 \\
\hline $\mathrm{Cu} 1-\mathrm{N} 11$ & $1.992(12)$ & 1.98701 & $\mathrm{Co} 1-\mathrm{N} 1$ & $2.057(19)$ & 2.05679 \\
\hline $\mathrm{Cu} 1-\mathrm{O} 21$ & $1.957(9)$ & 1.95157 & $\mathrm{Co} 1-\mathrm{N} 3$ & $2.022(19)$ & 2.02193 \\
\hline Cu1-N11_a & $1.992(12)$ & 1.98701 & - & - & - \\
\hline Bond angles & - & - & Bond angles & - & - \\
\hline $\mathrm{O} 3-\mathrm{Cu} 1-\mathrm{O} 21 \_\mathrm{a}$ & $88.5(3)$ & 88.426 & $\mathrm{O} 1-\mathrm{Co} 1-\mathrm{N} 1$ & $101.9(7)$ & 101.880 \\
\hline $\mathrm{O} 3-\mathrm{Cu} 1-\mathrm{N} 11$ & $97.5(4)$ & 97.572 & $\mathrm{O} 1-\mathrm{Co} 1-\mathrm{N} 3$ & $121.5(7)$ & 121.427 \\
\hline $\mathrm{O} 3-\mathrm{Cu} 1-\mathrm{O} 21$ & $88.5(3)$ & 88.426 & $\mathrm{O} 3-\mathrm{Co} 1-\mathrm{O} 1$ & $99.1(7)$ & 99.975 \\
\hline O3-Cu1-N11_a & $97.5(4)$ & 97.572 & $\mathrm{O} 3-\mathrm{Co} 1-\mathrm{N} 1$ & $106.0(8)$ & 106.019 \\
\hline O21-Cu1-O21_a & $176.1(4)$ & 176.852 & $\mathrm{O} 3-\mathrm{Co} 1-\mathrm{N} 3$ & $123.8(7)$ & 123.851 \\
\hline O21-Cu1-N11_a & $87.9(5)$ & 86.629 & $\mathrm{~N} 3-\mathrm{Co} 1-\mathrm{N} 1$ & $100.9(8)$ & 100.871 \\
\hline N11-Cu1-O21_a & $87.9(5)$ & 86.629 & - & - & - \\
\hline N11-Cu1-N11_a & $165.0(5)$ & 164.856 & - & - & - \\
\hline
\end{tabular}

Symmetry codes; 1: 1/2-x,+y,1-z, 2: -x,1-y,1-z; 1-x,-y,-z

\subsection{Spectroscopic Studies}

\subsubsection{FT-IR}

The spectra of the compounds were compared with those of the ligands (Table S1). Some new bands were found while some were shifted in the FTIR spectra of the compounds as shown in Figs. $3 \mathrm{a}$ and $3 \mathrm{~b}$. This shows the existence of coordination of the metal to the ligands. For $\mathbf{1}$, the broad absorption band at $3373 \mathrm{~cm}^{-1}$ is assigned to $v(\mathrm{O}-\mathrm{H})$ coordinated water. The free Biphenyl-4-carboxylic acid showed a broadband from $2979 \mathrm{~cm}^{-1}$ to $2546 \mathrm{~cm}^{-1}$ which was assigned to the $v(\mathrm{O}-\mathrm{H})$ of carboxylic acid present. This was shifted to $2091 \mathrm{~cm}^{-1}$ in the 
spectrum of $\mathbf{1}$ as a result of deprotonation and coordination of the Biphen ion to the metal [26]. $\Delta v$ of the anti-symmetric and symmetric stretching of the $\mathrm{COO}^{-}$bonded to $\mathrm{Cu}$ is $225 \mathrm{~cm}^{-1}$ confirming a monodentate coordination mode [27]. Weak peaks at $652 \mathrm{~cm}^{-1}$ and $473 \mathrm{~cm}^{-1}$ are characteristic of $\mathrm{Cu}-\mathrm{N}$ and $\mathrm{Cu}-\mathrm{O}$ respectively. For 2 , the sharp peaks at 1580 and $1360 \mathrm{~cm}^{-1}$ correspond to the anti-symmetric and symmetric stretching of the $\mathrm{COO}^{-}$bonded to $\mathrm{Co}$ respectively. Smaller peaks in the range of $1294-889 \mathrm{~cm}^{-1}$ and $889-552 \mathrm{~cm}^{-1}$ correspond to the in- plane and out of plane bending of the $\mathrm{C}-\mathrm{H}$ group of the benzene ring of the BDC linker. Peaks around $552 \mathrm{~cm}^{-1}$ and $495 \mathrm{~cm}^{-1}$ are characteristic of Co-N and Co-O respectively. The sharp narrow peak at $3123 \mathrm{~cm}^{-1}$ is assigned to aromatic $\mathrm{C}-\mathrm{H}$ stretching vibration of the ligands (Fig. 3b).

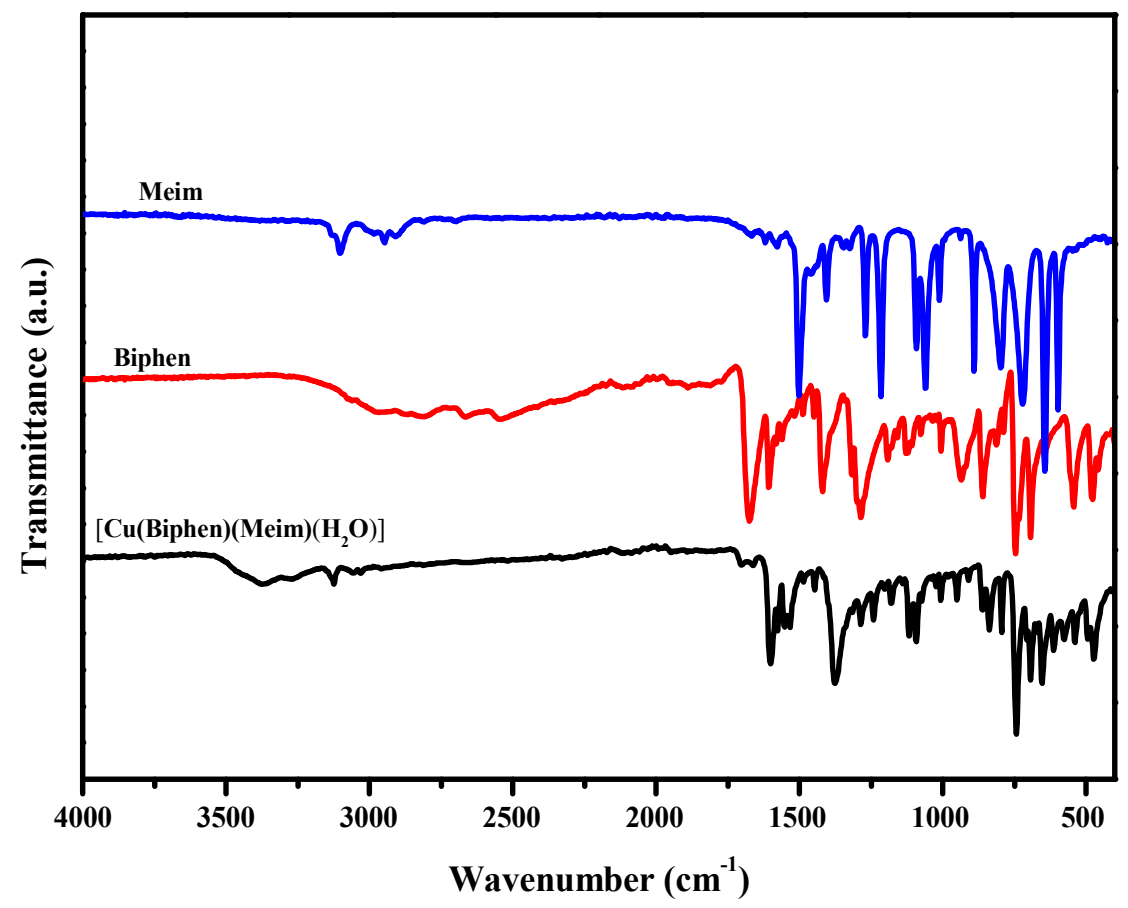

Figure 3a: FTIR spectra of 1 and its ligands 


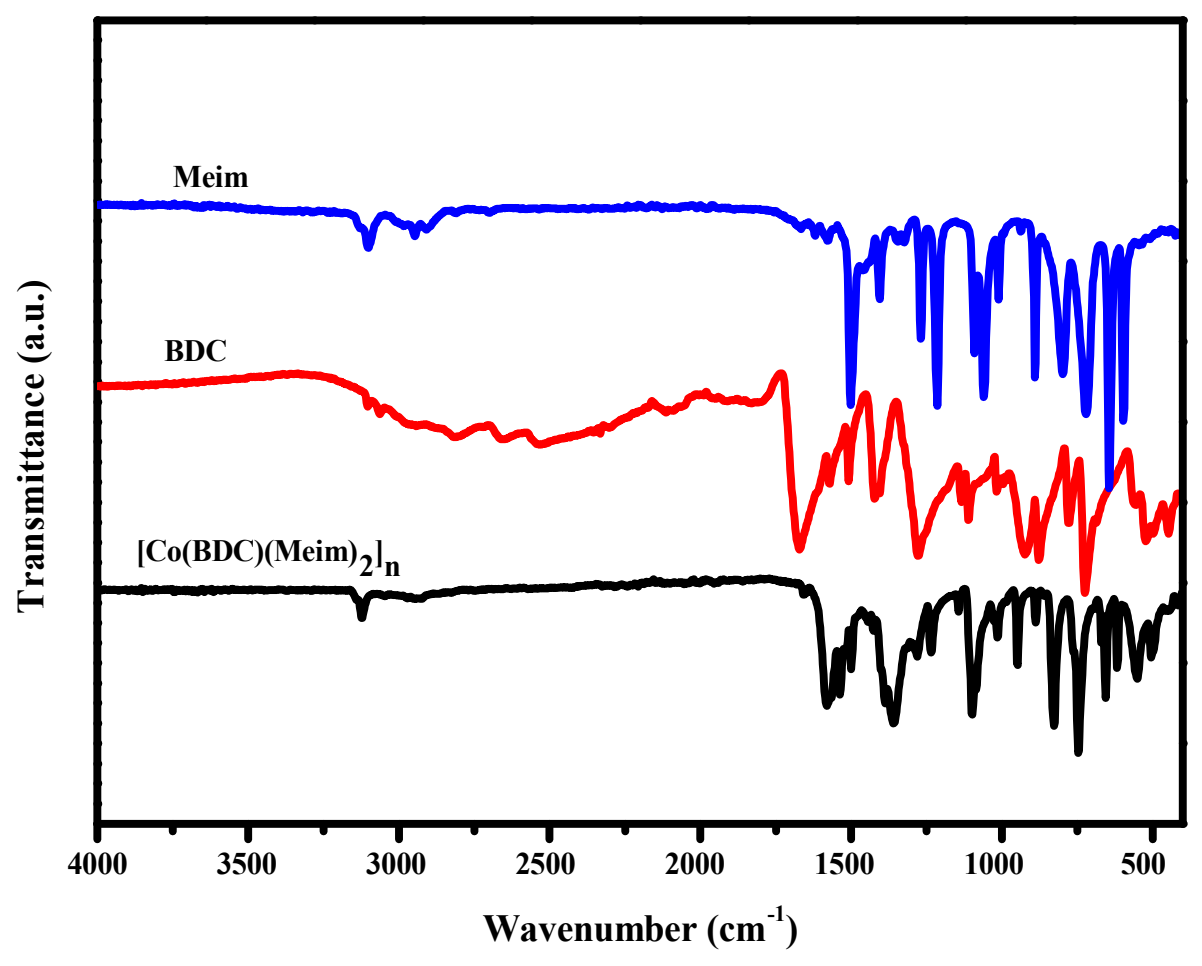

Figure 3b: FTIR spectra of 2 and its ligands

\subsubsection{UV-Vis Spectroscopy}

The electronic data of the compounds were recorded in solid-state and at room temperature (Table 1c.) In the UV region of the spectrum of $\mathbf{1}$, intra-ligand transition results in absorption maxima at $266 \mathrm{~nm}$ assigned to $\pi \rightarrow \pi^{*} / \mathrm{n} \rightarrow \pi^{*}$ transitions and a near visible band $351 \mathrm{~nm}$ assigned to LMCT (Fig. S3). The broad band in the visible region suggests the donation of electrons by the ligands to the $\mathrm{Cu}^{2+}$ ion with absorption maxima at $552 \mathrm{~nm}$ assigned to $\mathrm{d}-\mathrm{d}$ transitions $\left({ }^{2} \mathrm{E}_{\mathrm{g}}-{ }^{2} \mathrm{~T}_{2 \mathrm{~g}}\right)$ [28]. In 2 the absorption band observed at $225 \mathrm{~nm}$ is assigned to $\pi \rightarrow$ $\pi * / \mathrm{n} \rightarrow \pi *$ transitions while the two broad bands in the visible region (Fig. S4). The band at $431 \mathrm{~nm}$ is as a result of ligand-metal charge transfer (LMCT) while the band at $617 \mathrm{~nm}$ indicates the transition of spin-allowed tetrahedral $\mathrm{Co}^{2+},{ }^{4} \mathrm{~A}_{2}(\mathrm{~F}) \rightarrow{ }^{4} \mathrm{~T}_{1}(\mathrm{~F})[29]$. 
Table 1c: Electronic data of ligands and compounds

\begin{tabular}{lll}
\hline Compounds & Wavelength, $\lambda_{\max }, \mathrm{nm}\left(\mathrm{E}, \mathrm{cm}^{-1}\right)$ & Assignment \\
\hline Biphen & $225(44,449)$ & $\pi-\pi^{*}$ \\
& $285(35,092)$ & $\pi-\pi^{*} / \mathrm{n}-\pi^{*}$ \\
BDC & $211(47,399)$ & $\pi-\pi^{*}$ \\
& $324(30,868)$ & $\pi-\pi^{*} / \mathrm{n}-\pi^{*}$ \\
Meim & $223(44,848)$ & $\pi-\pi^{*}$ \\
$\mathbf{1}$ & $266(37,598)$ & $\pi-\pi^{*} / \mathrm{n}-\pi^{*}$ \\
& $351(28,494)$ & $\mathrm{LMCT}$ \\
& $552(18,118)$ & ${ }^{2} \mathrm{E}_{\mathrm{g}}-{ }^{2} \mathrm{~T}_{2 \mathrm{~g}}$ \\
$\mathbf{2}$ & $225(44,449)$ & $\pi-\pi^{*} / \mathrm{n}-\pi^{*}$ \\
& $431(23,204)$ & ${ }^{4} \mathrm{~A}_{2}(\mathrm{~F})-{ }^{4} \mathrm{~T}_{1}(\mathrm{~F})$ \\
& $617(16,209)$ & ${ }^{4} \mathrm{~A}_{2}(\mathrm{~F})-{ }^{4} \mathrm{~T}_{1}(\mathrm{P})$ \\
\hline
\end{tabular}

\subsubsection{Photoluminescence Spectra}

Luminescent measurements were carried out on the compounds as prepared in the solid state and at room temperature. The photoluminescent (PL) spectra of the compounds and their free ligands are shown in Fig. 3c \& 3d. 1 emits strongly at $430 \mathrm{~nm}$ upon excitation at $297 \mathrm{~nm}$. The emission spectrum of the free ligand shows a main peak at $431 \mathrm{~nm}$ assigned to $\mathrm{n}-\pi^{*} / \pi^{*}-\pi$ transitions of the ligand [30]. The similar emission bands exhibited by the compound and the ligand suggests that the emission of $\mathbf{1}$ could be attributed to ligand-centered electronic transitions perturbed by the coordinated metal ions, leading to ligand to metal charge transfer (LMCT). The free BDC ligand displays one main fluorescent emission at $366 \mathrm{~nm}$ which is assigned to $n-\pi^{*} / \pi^{*}-\pi$ transitions of the ligand. The emission band of $\mathbf{2}$ is slightly red shifted (about $19 \mathrm{~nm}$ ) with reduced intensity $\left(\lambda_{\mathrm{em}}=384 \mathrm{~nm}\right)$. This may be assigned to ligand to metal charge transfer (LMCT) because of chelation to the metal [31]. 


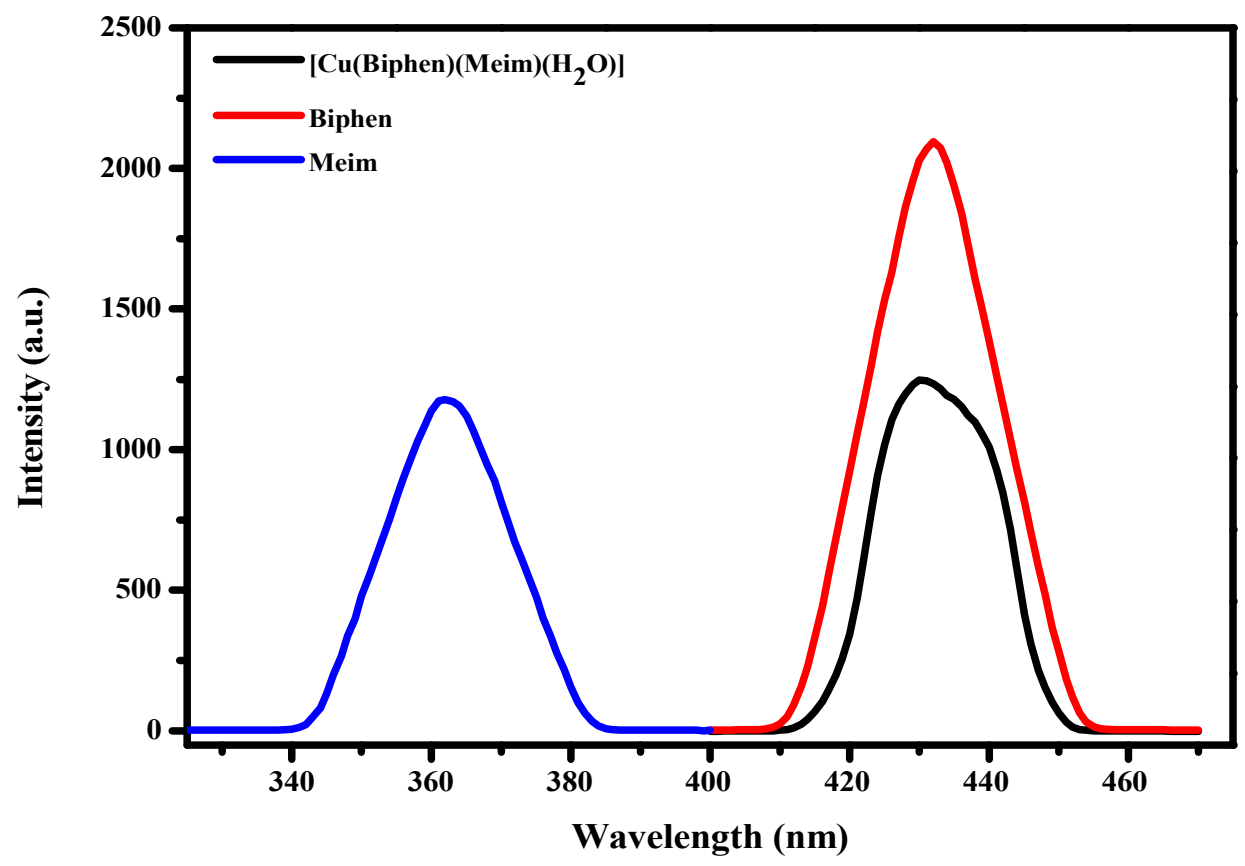

Fig. 3c: PL Spectra of $\left[\mathrm{Cu}(\right.$ Biphen $)($ Meim $\left.)\left(\mathrm{H}_{2} \mathrm{O}\right)\right]$ and its ligand in solid state $\left(\lambda_{\mathrm{ex}}=297 \mathrm{~nm}\right)$

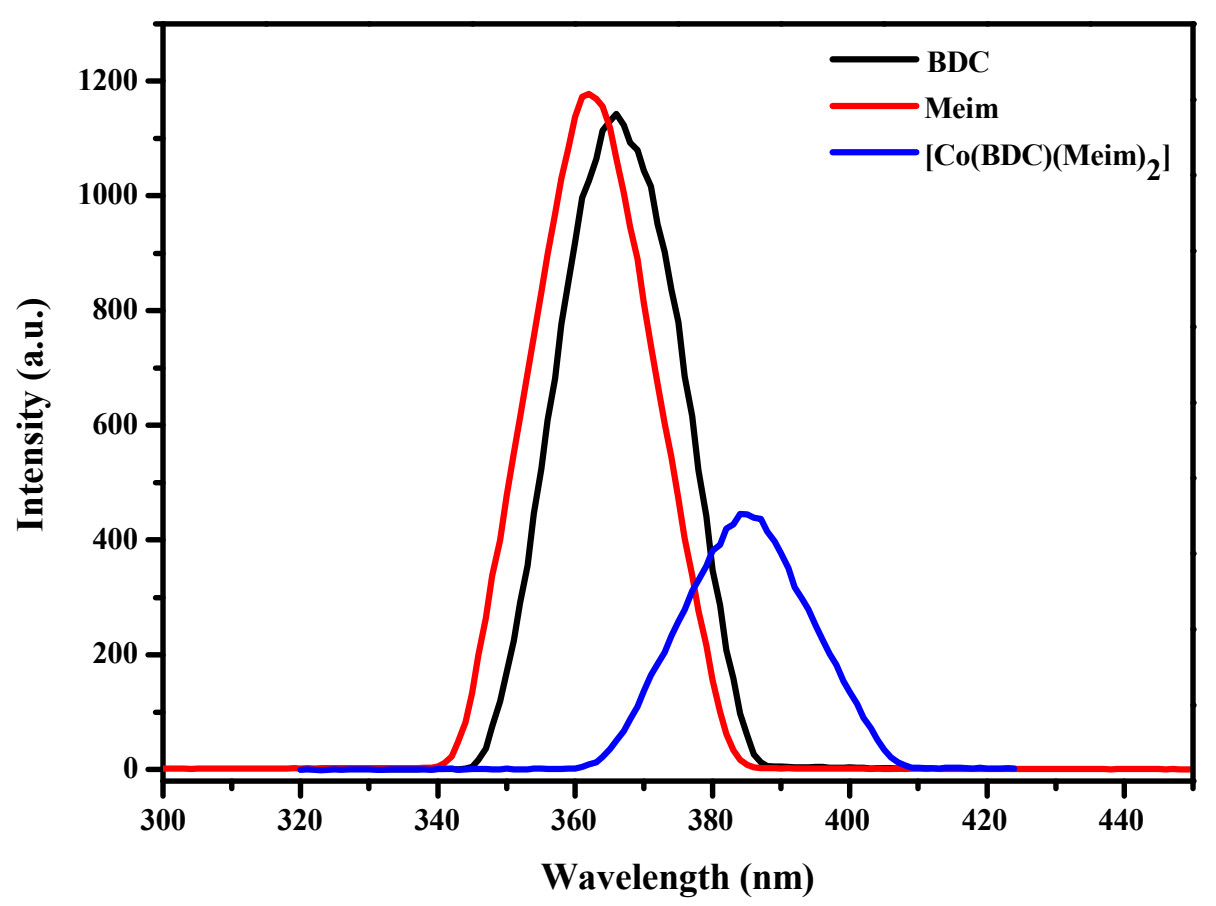

Fig. 3d: PL Spectra of $\left[\mathrm{Co}(\mathrm{BDC})(\text { Meim })_{2}\right]_{\mathrm{n}}$ and its ligand in solid state $\left(\lambda_{\mathrm{ex}}=265 \mathrm{~nm}\right)$ 


\subsection{Thermal Analysis}

Fig. 3e showed the thermal decomposition patterns of the compounds. The TGA curve of 1 shows the first decomposition stage having a percentage weight loss of $1.71 \%$ (2.80\%) (exp. (calcd.)). This corresponds to the loss of a molecule of coordinated water at around $137{ }^{\circ} \mathrm{C}$. The second stage of the decomposition between $216-357^{\circ} \mathrm{C}$ is attributed to gradual loss of the ligands (two molecules of Meim and one molecule of Biphen) with percentage weight loss

of $41.62 \%(40.64 \%)$ (exp. (calcd.)) and a collapse of the framework between $415-540{ }^{\circ} \mathrm{C}$ leaving a residue of $\mathrm{CuO}$ with a total weight of $12.53 \%(9.7 \%)$ (exp. (cald.)). The TGA curve of 2 shows three decomposition steps. There was no weight loss until decomposition at $200^{\circ} \mathrm{C}$, indicating that no guest molecules are present in the pores of the framework. A weight loss of $70.12 \%$ exp., calcd. $68.2 \%$ is ascribed to the loss of the methylimidazole ligand and a total collapse of the framework at $410^{\circ} \mathrm{C}$ is the loss of the $\mathrm{BDC}$ ligand. The final residue of $\mathrm{CoO}$ has a total weight of $19.25 \%(26.5 \%)$ (exp. (cald.)). 


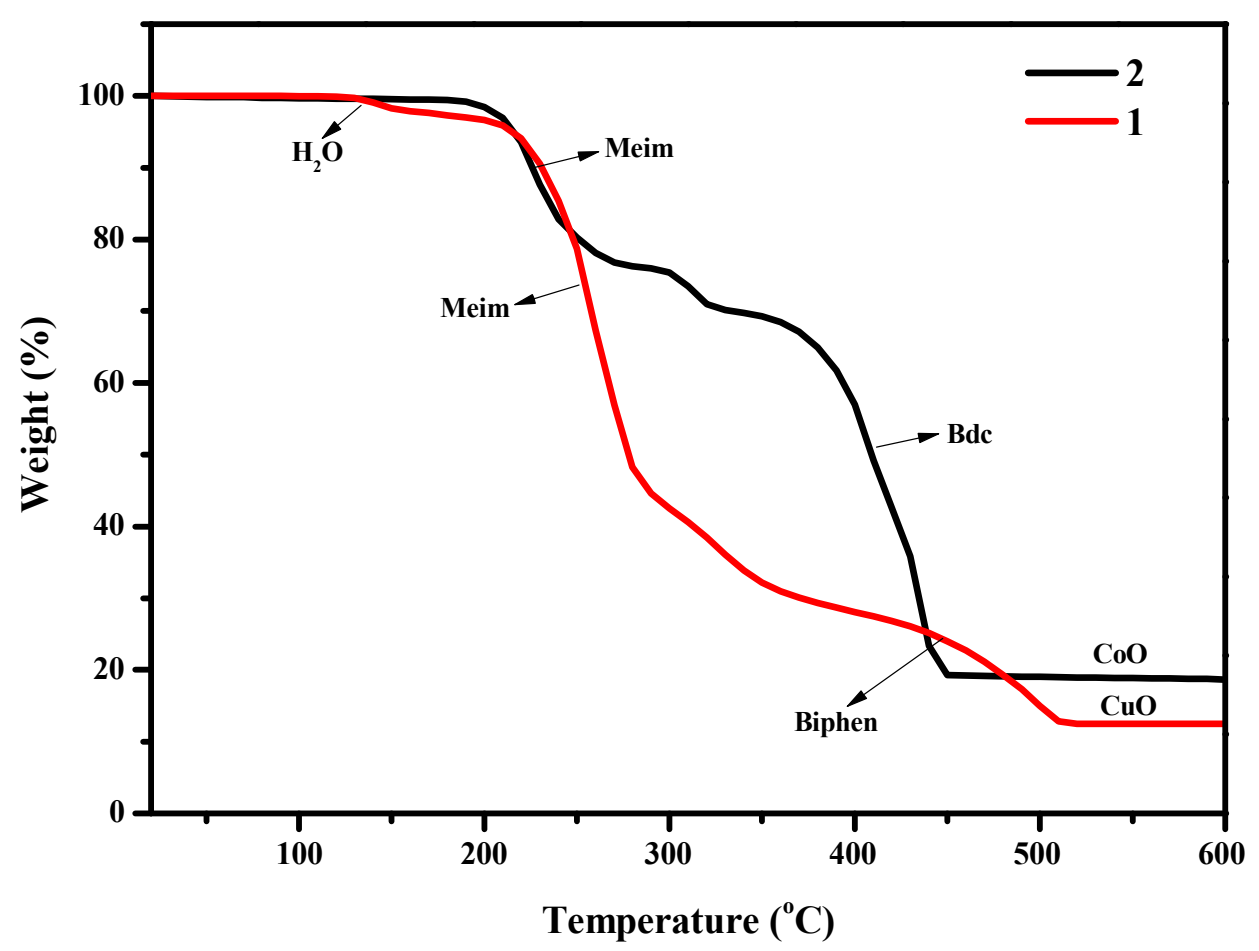

Fig. 3e: TGA Curve of 1 and $\mathbf{2}$

\subsection{Fluorescence Sensing}

Compound 1 displayed a clear response sensitivity to the nitroaromatics examined in the order 4NP $>$ 4NA $>$ NB as shown in Fig. 4a. The emission bands were reduced rapidly following incremental addition of nitroaromatic compounds up to $3 \mathrm{mM}$ (Fig. 4b, Fig. 4d \& Fig. 4f). The quenching capacities are $96.8 \%$ for $4 \mathrm{NP}, 85.9 \%$ for $4 \mathrm{NA}$ and $63.10 \%$ for NB respectively (Fig. S5). The quenching efficiency of the nitro analytes were evaluated using the Stern-Volmer (S-V) equation, Io/I $=\mathrm{K}_{\mathrm{SV}}[\mathrm{M}]+1$ [32], in which Io and I are the emission intensities of maximum emission band before and after the addition of nitroaromatic compounds, $[\mathrm{M}]$ represents the molar concentration of the nitro analytes $(\mathrm{mM})$, and $\mathrm{K}_{\mathrm{SV}}$ is the $\mathrm{S}-\mathrm{V}$ constant $\left(\mathrm{M}^{-1}\right)$. Good linear correlations were obtained $\left(\mathrm{R}^{2}>0.9\right)$ and presented in Fig. 4c, Fig. $4 \mathrm{e} \&$ 4g. Furthermore, the limits of detection were calculated based on $3 \sigma / \mathrm{k}(\sigma=$ standard deviation; 
$\mathrm{k}=$ slope of emission intensity versus concentration plot) for the three nitro analytes (Table 1d). Compound 2 was also found to be highly selective towards nitroaromatic compounds with significant quenching of its luminescent intensities. The luminescent quenching towards nitroaromatics is in the order 4NA $>4 \mathrm{NP}>\mathrm{NB}$ as shown in Fig. 5a. The quenching capacities are $96.6 \%, 88.7 \%$ and $85.7 \%$ for $4 \mathrm{NA}, 4 \mathrm{NP}$ and NB respectively (Fig. S6). To further investigate the selectivity of $\mathbf{2}$ towards nitroaromatic compounds, a batch of suspensions of $\mathbf{2}$ in DMF was dispersed in the nitro analytes with gradual increment in concentration. The emission band was found to reduce as the concentration of nitro analytes increased up to $3 \mathrm{mM}$ (Fig. 5b, Fig. 5d \& Fig. 5f). The dose-response curves (S-V plot) showed good linearity $\left(\mathrm{R}^{2}>\right.$ $0.9)$ and high quenching constants $\left(\mathrm{K}_{\mathrm{SV}}\right)$ as shown in Fig 5c, Fig. 5e \& Fig. 5g. The limits of detection are low and in the range $1.66-2.93 \mathrm{ppm}$ (Table 1d).

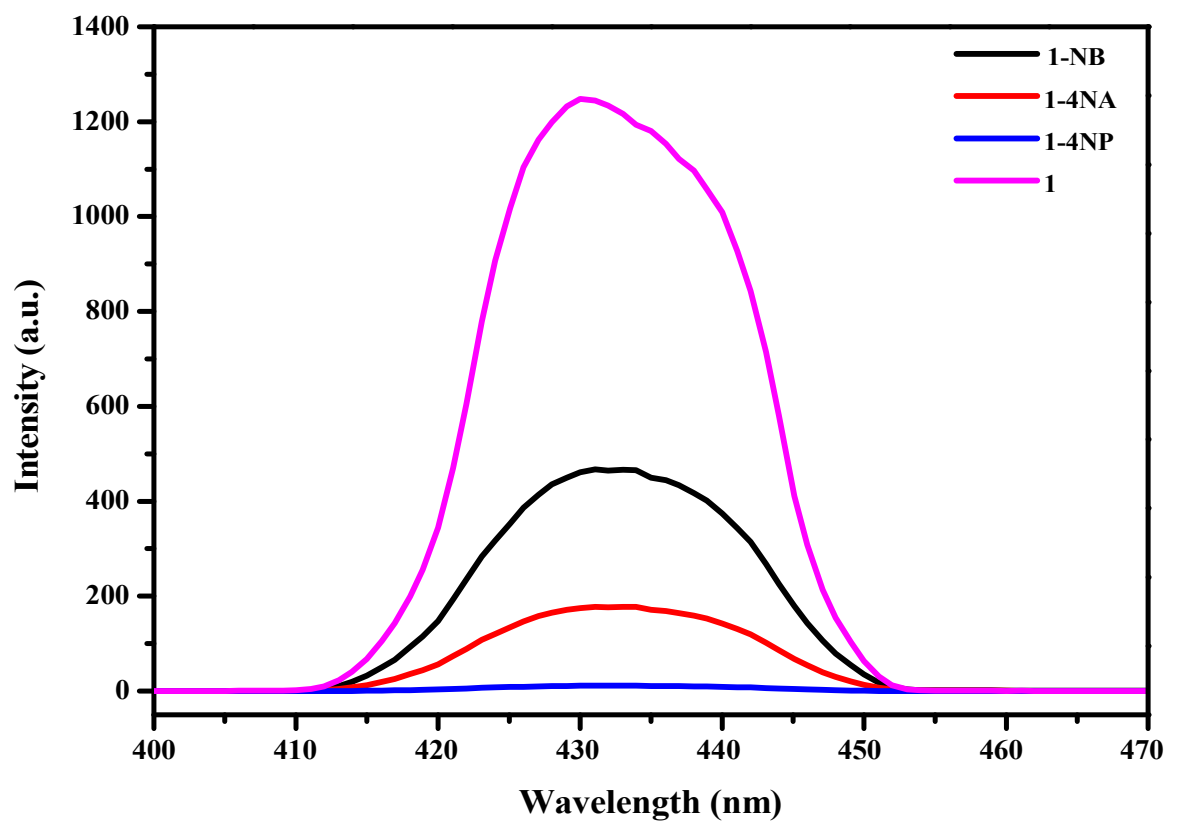

Fig. 4a: Luminescence intensities of $\mathbf{1}$ when immersed in different nitro analytes. 


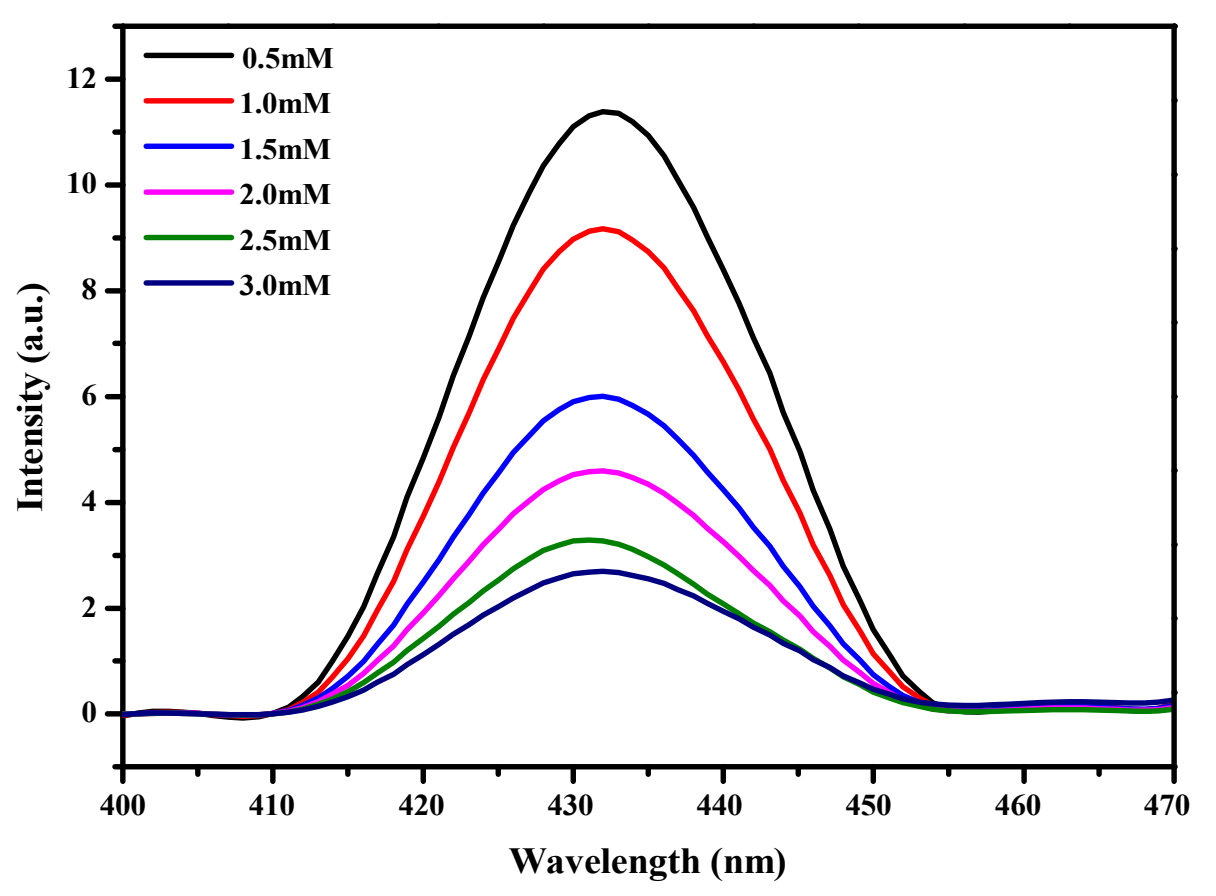

Fig. 4b: Emission spectra of 1 dispersed in DMF with incremental addition of 4NP

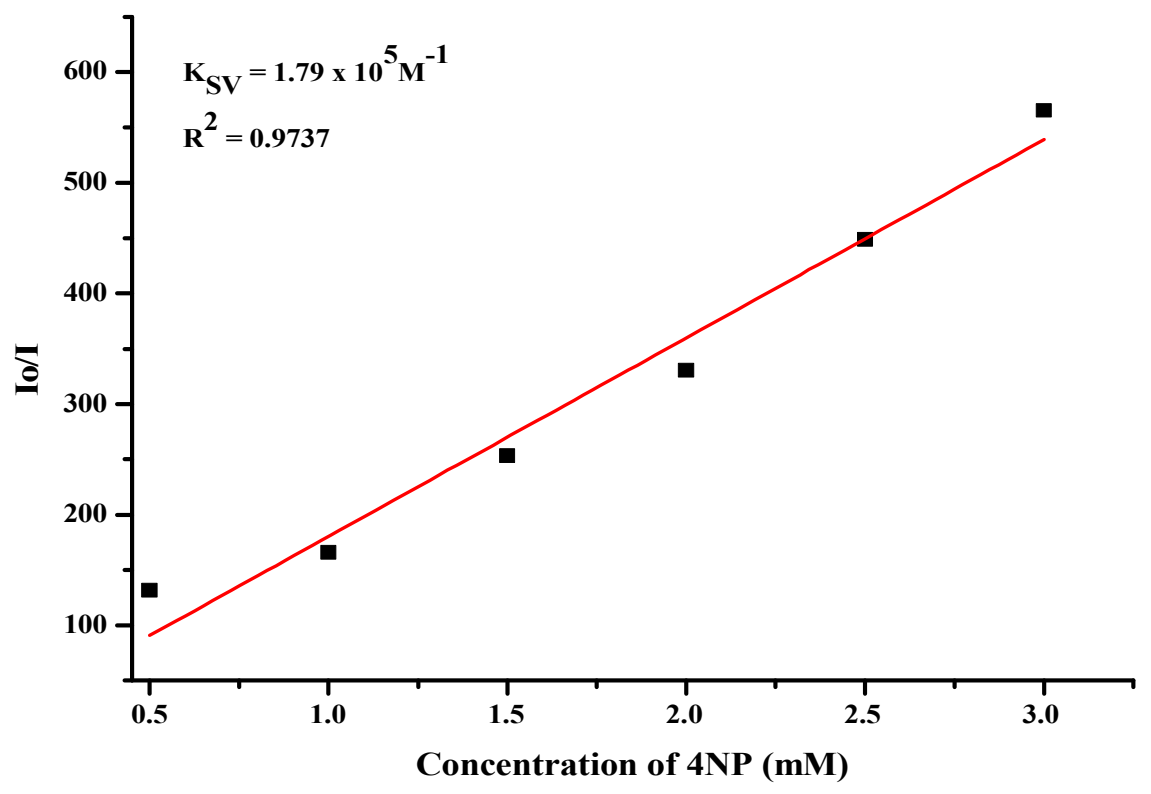

Fig. 4c: Stern-Volmer plot of $\mathbf{1}$ in 4-nitrophenol 


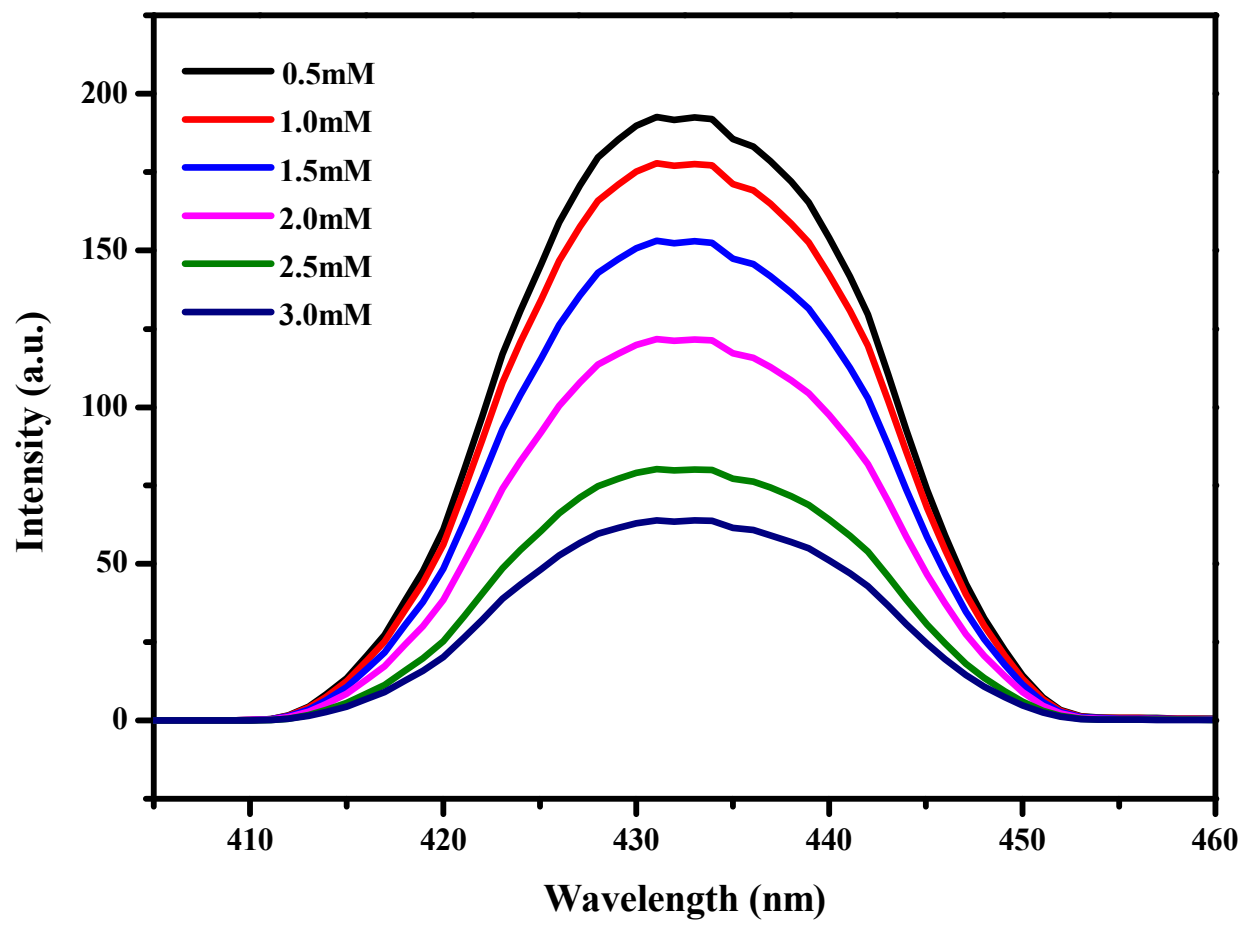

Fig. 4d: Emission spectra of $\mathbf{1}$ dispersed in DMF with incremental addition of 4NA

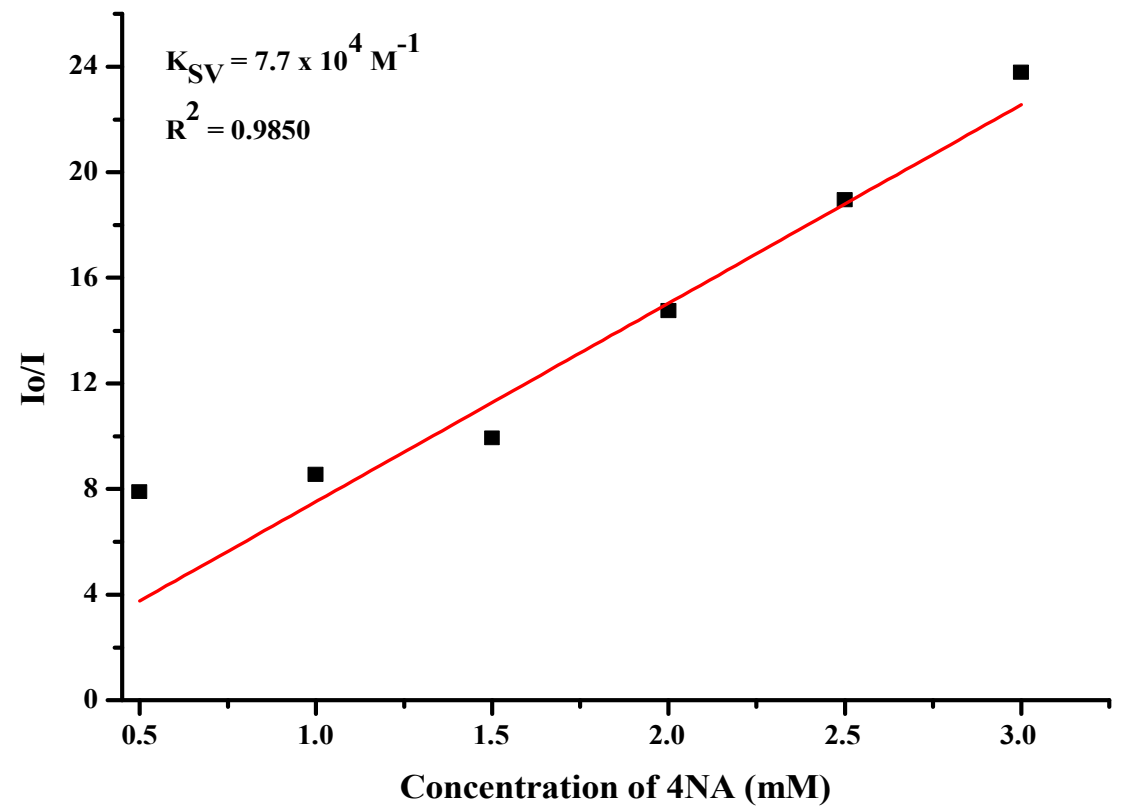

Fig. 4e: Stern-Volmer plot of $\mathbf{1}$ in 4-nitroaniline 


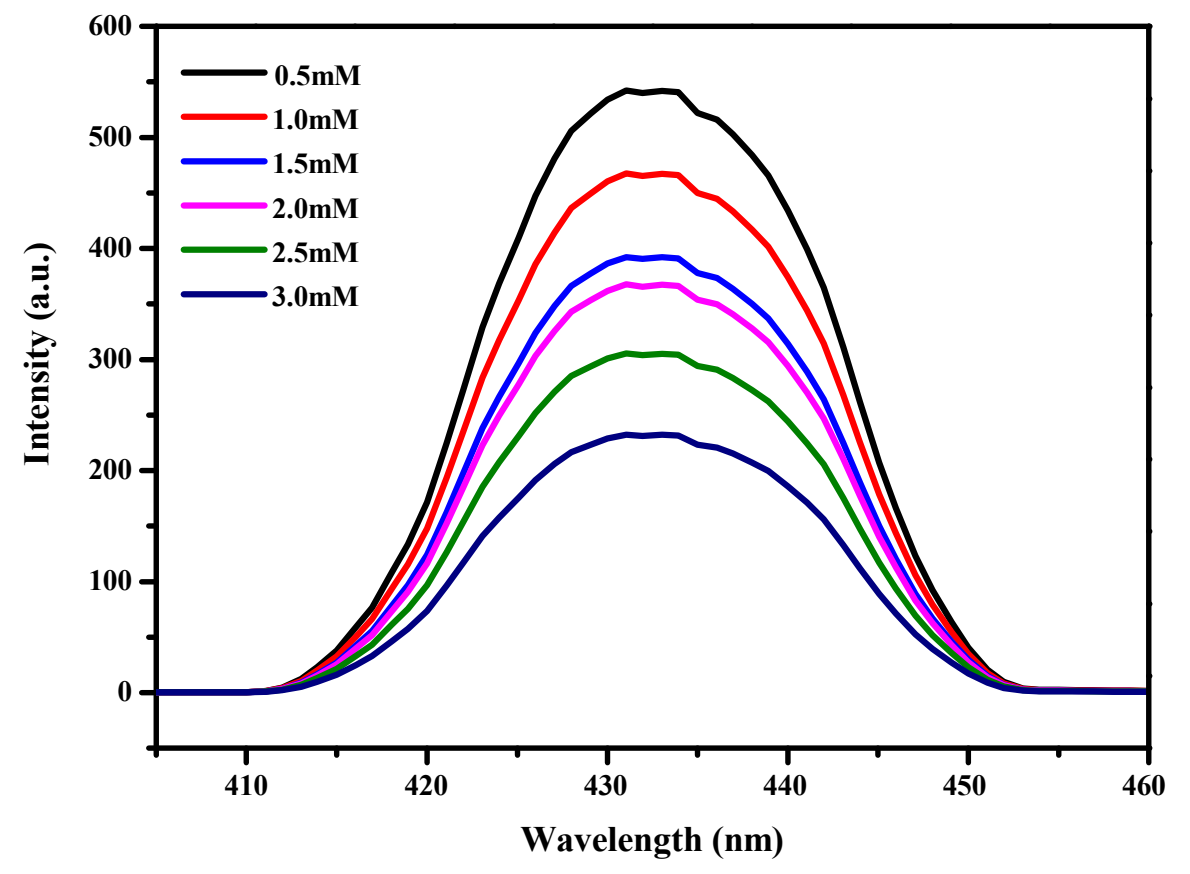

Fig. 4f: Emission spectra of $\mathbf{1}$ dispersed in DMF with incremental addition of NB

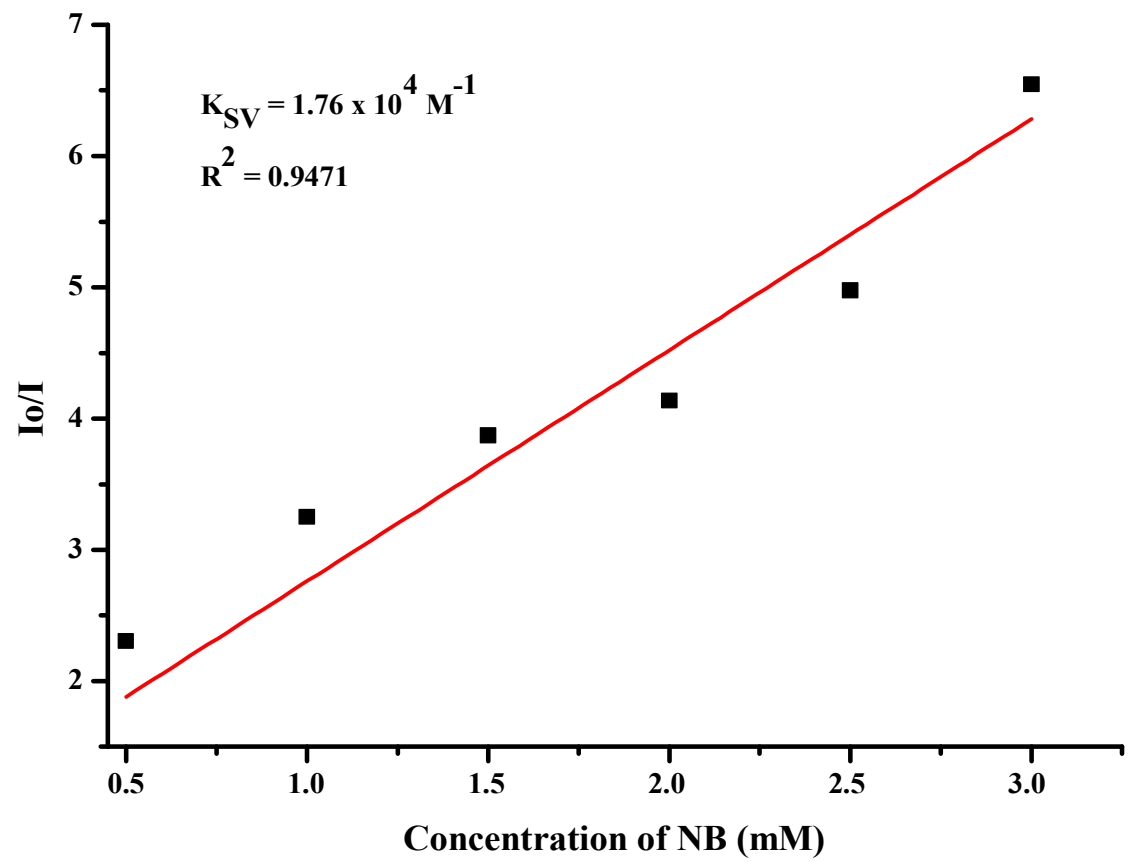

Fig. 4g: Stern-Volmer plot of $\mathbf{1}$ in nitrobenzene 


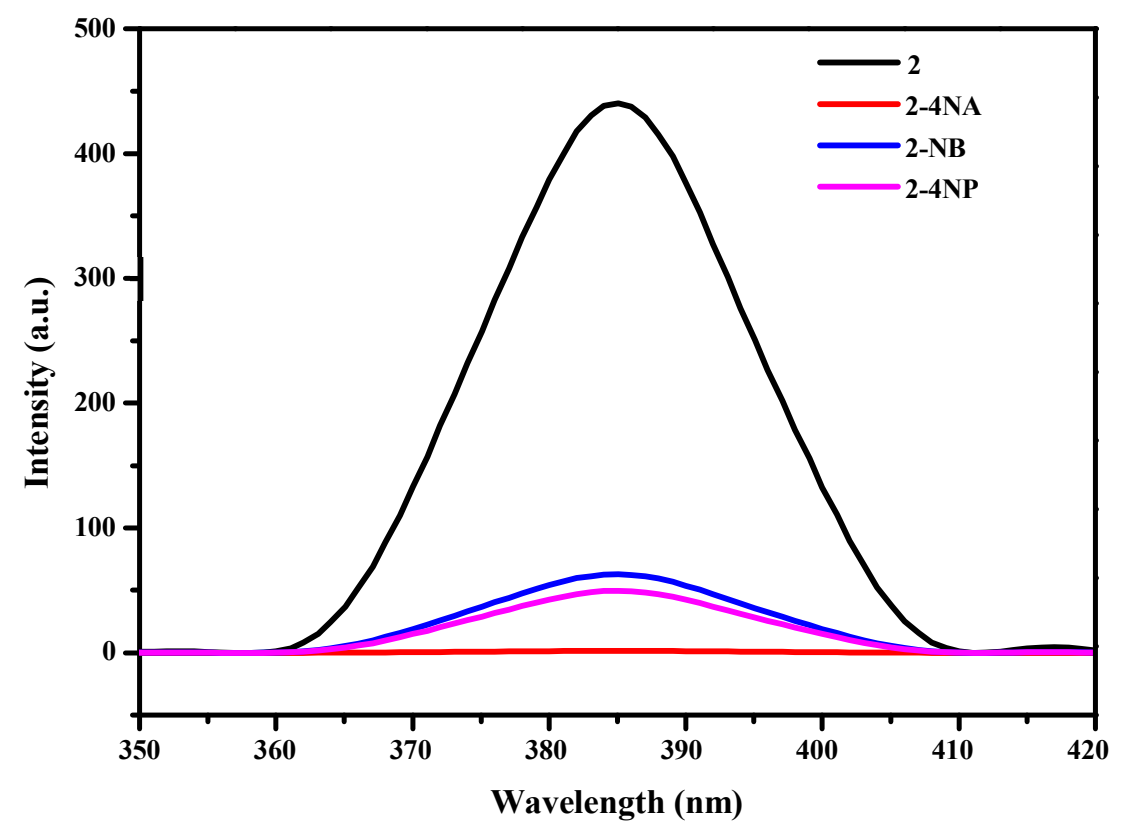

Fig. 5a: Luminescence intensities of $\mathbf{2}$ when immersed in different nitro analytes

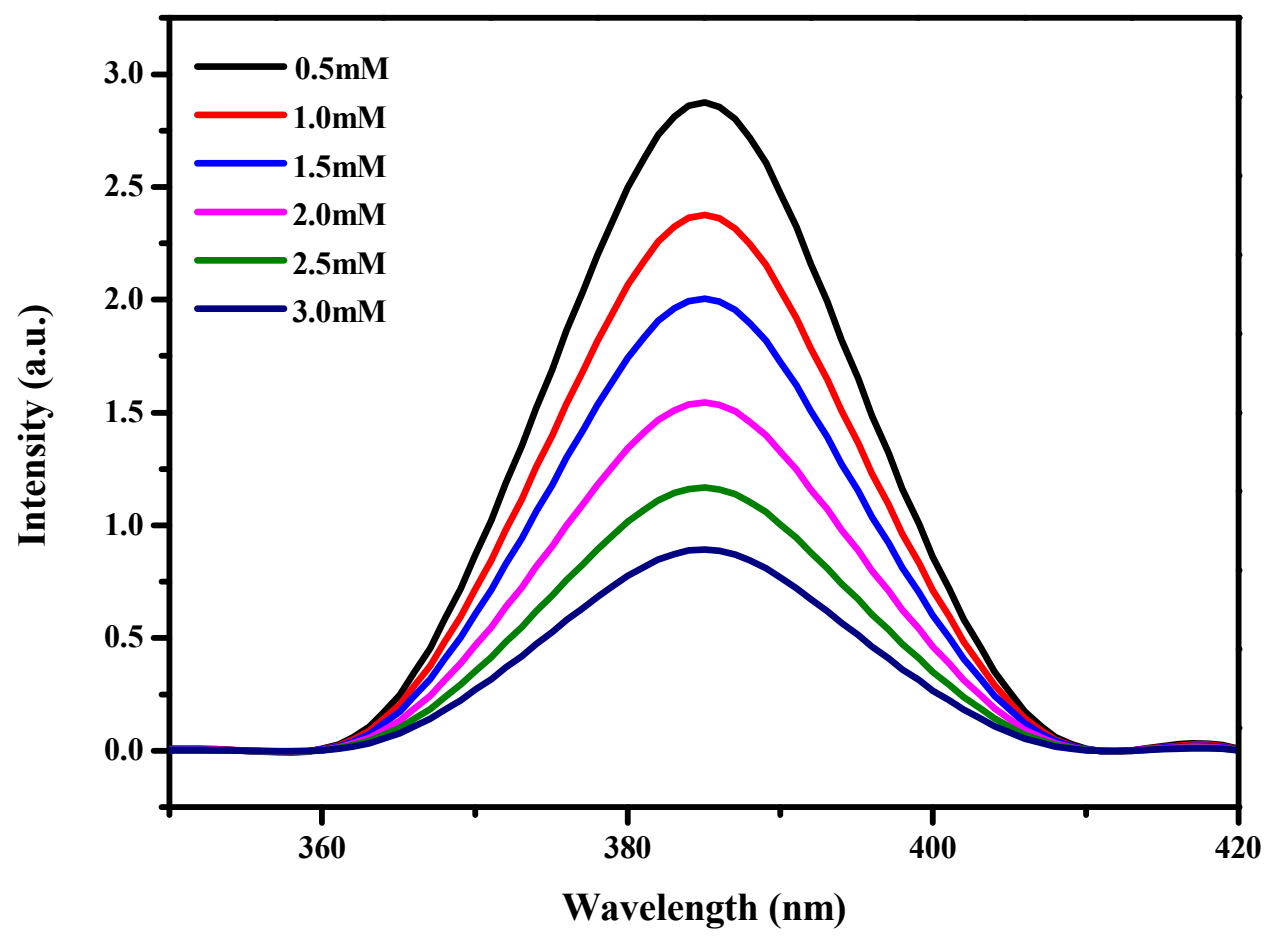

Fig. 5b: Emission spectra of $\mathbf{2}$ dispersed in DMF with incremental addition of 4NA 


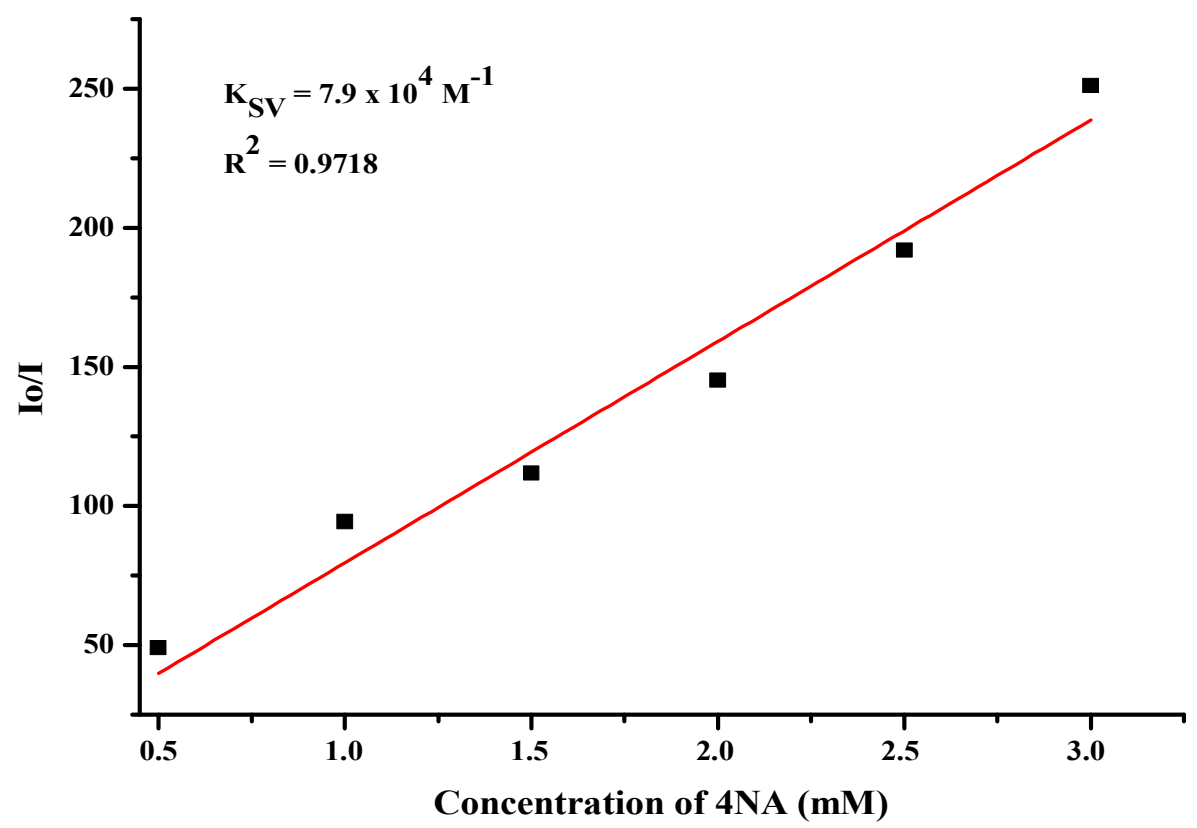

Fig. 5c: Stern-Volmer plot of $\mathbf{2}$ in 4-nitroaniline

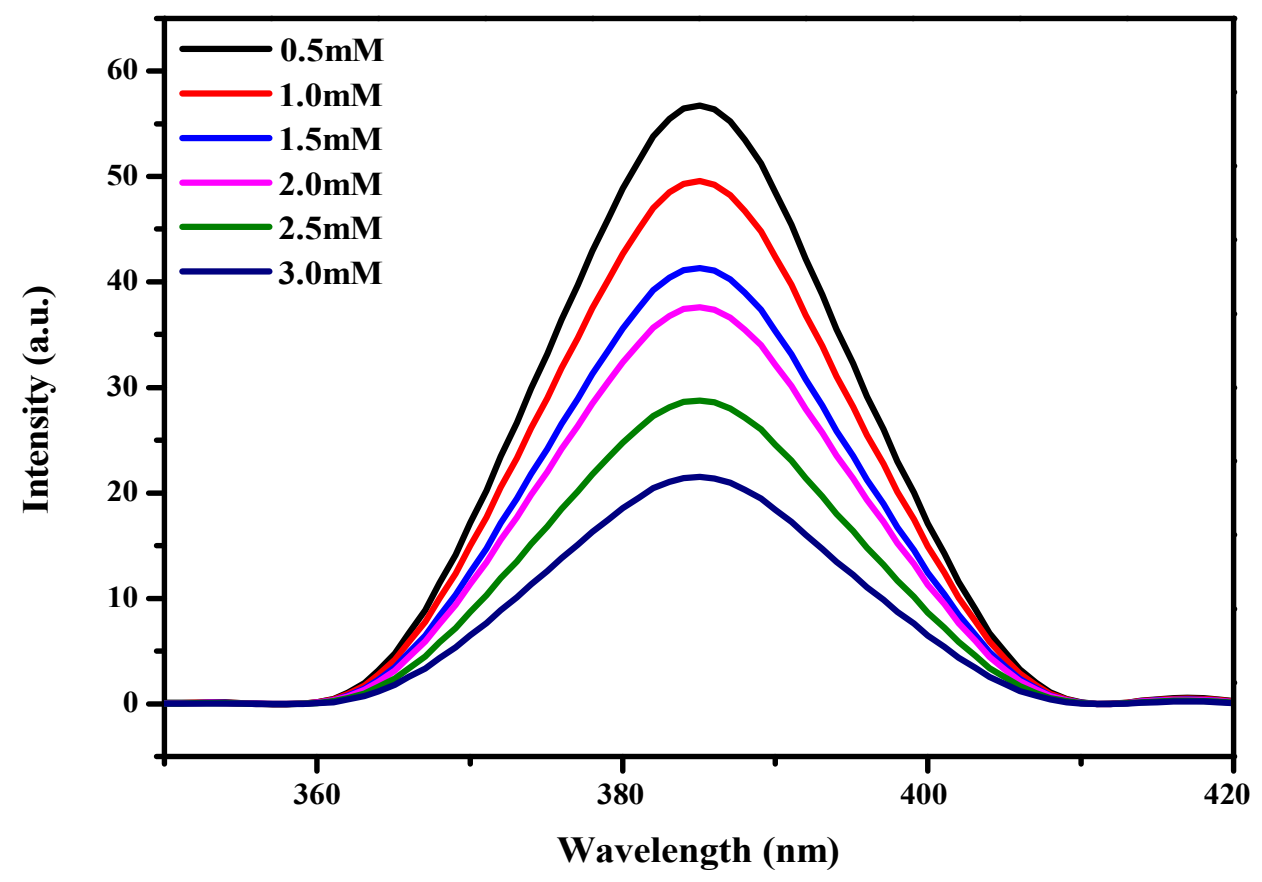

Fig. 5d: Emission spectra of $\mathbf{2}$ dispersed in DMF with incremental addition of 4NP 


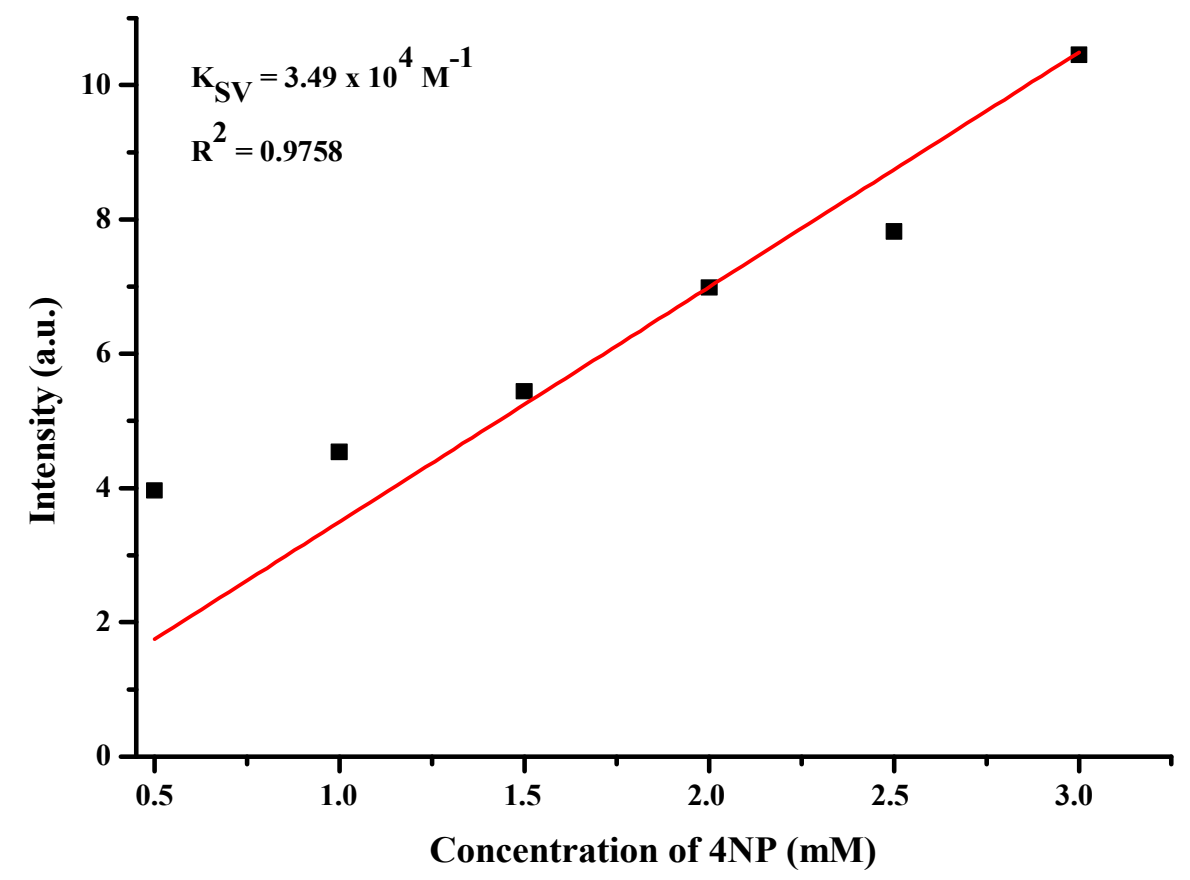

Fig. 5e: Stern-Volmer plot of $\mathbf{2}$ in 4-nitrophenol

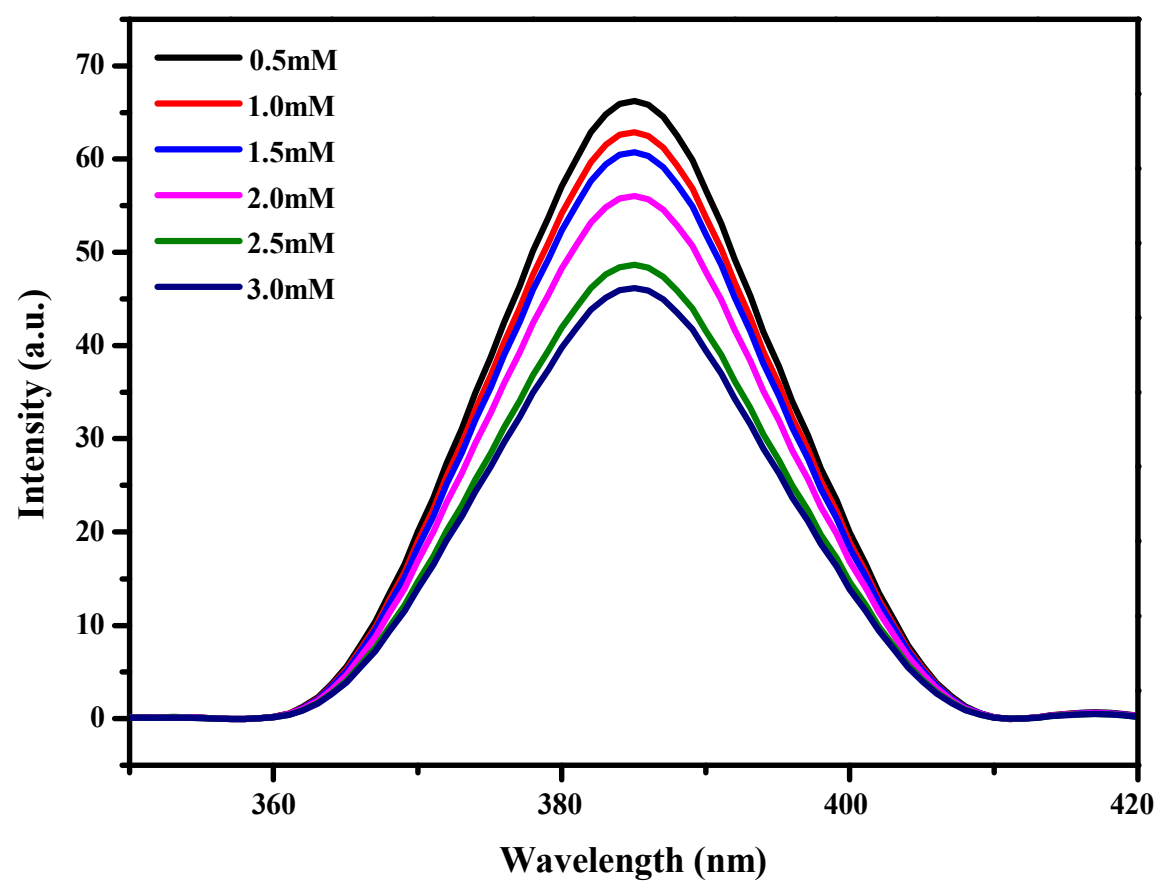

Fig. 5d: Emission spectra of $\mathbf{2}$ dispersed in DMF with incremental addition of NB 


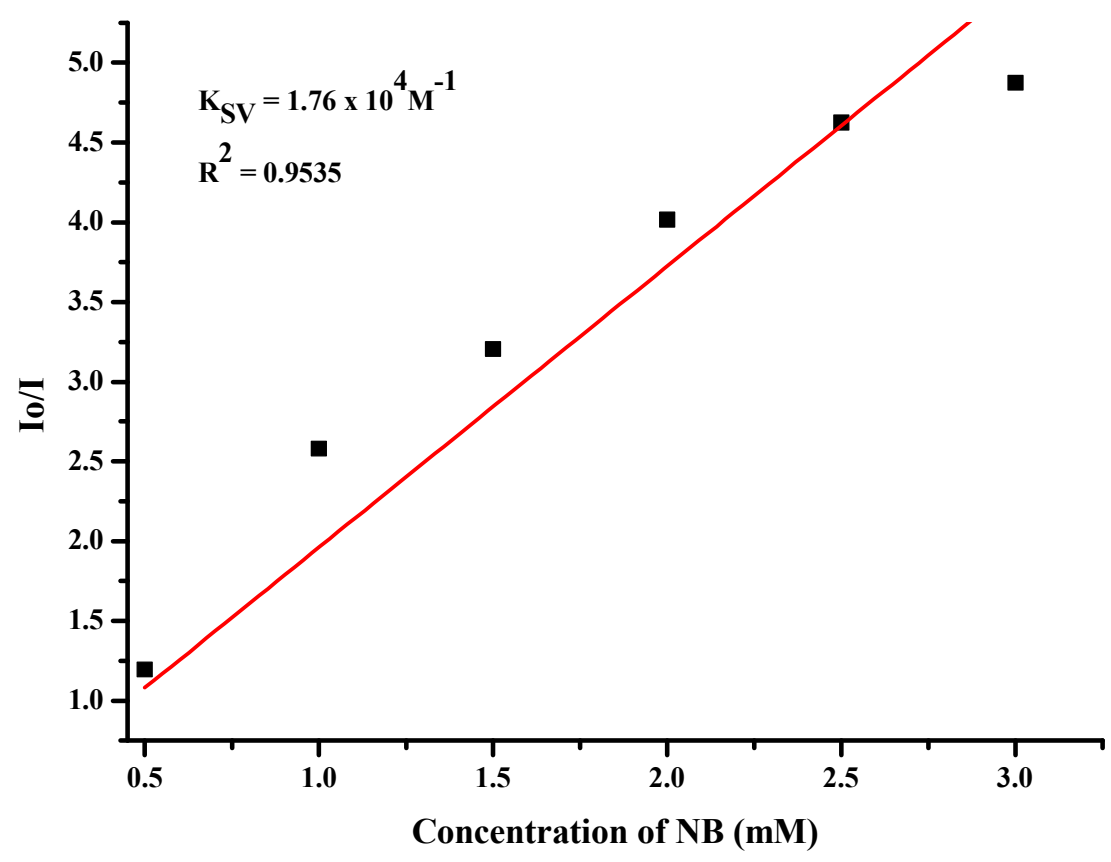

Fig. 5g: Stern-Volmer plot of $\mathbf{2}$ in nitrobenzene

Table 1d: $K_{S V}$ and LOD values of nitroaromatic compounds using $\mathbf{1}$ and $\mathbf{2}$ as sensors

\begin{tabular}{|l|c|c|}
\hline Nitroaromatic compounds & Ksv $\left(\mathbf{M}^{-\mathbf{1}}\right)$ & LOD (ppm) \\
\hline & $\mathbf{1}$ & 2.67 \\
\hline 4NA & $7.7 \times 10^{4}$ & 13.07 \\
\hline 4NP & $1.79 \times 10^{5}$ & 1.84 \\
\hline NB & $1.76 \times 10^{4}$ & 1.66 \\
\hline & $\mathbf{2}$ & 2.93 \\
\hline 4NA & $7.9 \times 10^{4}$ & 1.95 \\
\hline 4NP & $3.49 \times 10^{4}$ & \\
\hline NB & $1.76 \times 10^{4}$ & \\
\hline
\end{tabular}




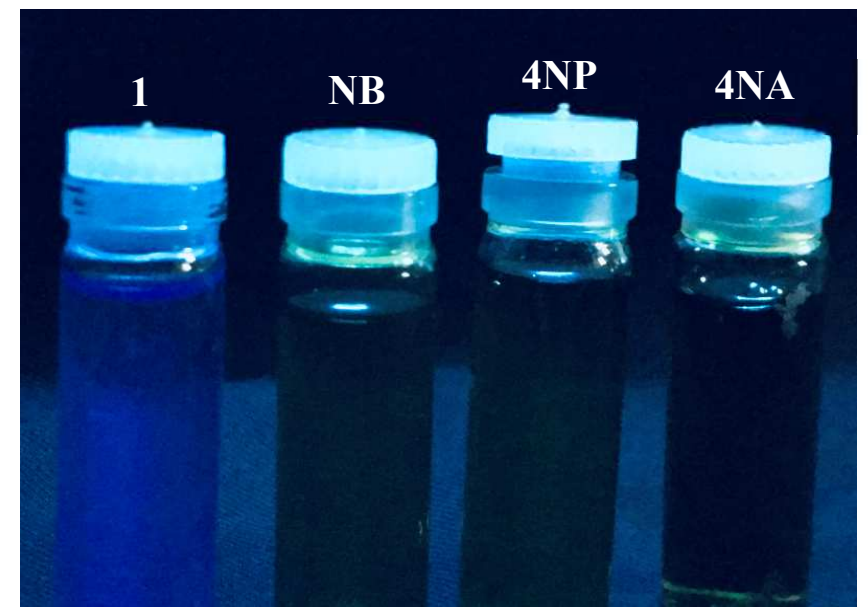

Fig. 5h: Photographs of $\mathbf{1}$ before and after immersion in different nitro analytes under UV light

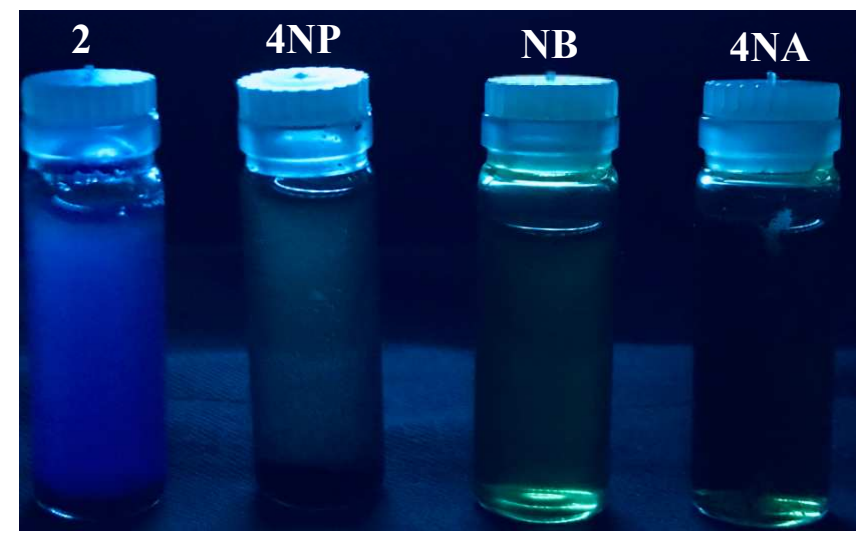

Fig. 5i: Photographs of $\mathbf{2}$ before and after immersion in different nitro analytes under UV light

\subsubsection{Quenching mechanism}

The possible quenching mechanism by nitroaromatic compounds was further examined. Firstly, the PXRD patterns of $\mathbf{1}$ and $\mathbf{2}$ were collected after immersion in the nitro-analytes to monitor the stability of the compounds. The PXRD patterns of the compounds were observed to be consistent with the simulated patterns which indicates high structural integrity and stability (Fig. 6a \& 6b). Thus, the luminescence quenching is not caused by the collapse of the structure. Secondly, from the structural characterization of the compounds, the ligands of the CPs are $\pi$-electron rich. The quenching effect may result from Photoinduced Electron Transfer (PET) attributable to donor-acceptor electron transfer mechanism [33, 34] because the nitro- 
group is a characteristic electron withdrawing substituent. Therefore, upon excitation, the excited electrons of the CPs could transfer to the LUMO of the nitroaromatic compounds, which causes the quenching effect. To further understand the quenching phenomena by electron transfer, competition experiment was carried out by $\mathrm{CP}$ immersion in aniline, comprising an electron donor substituent. Results revealed that there was no significant reduction in the luminescent intensity of the compounds when treated with aniline and incremental addition of aniline up to $3 \mathrm{mM}$ enhanced the fluorescent intensities (Fig. S7 \& S8). This observation agrees with literature report [35].

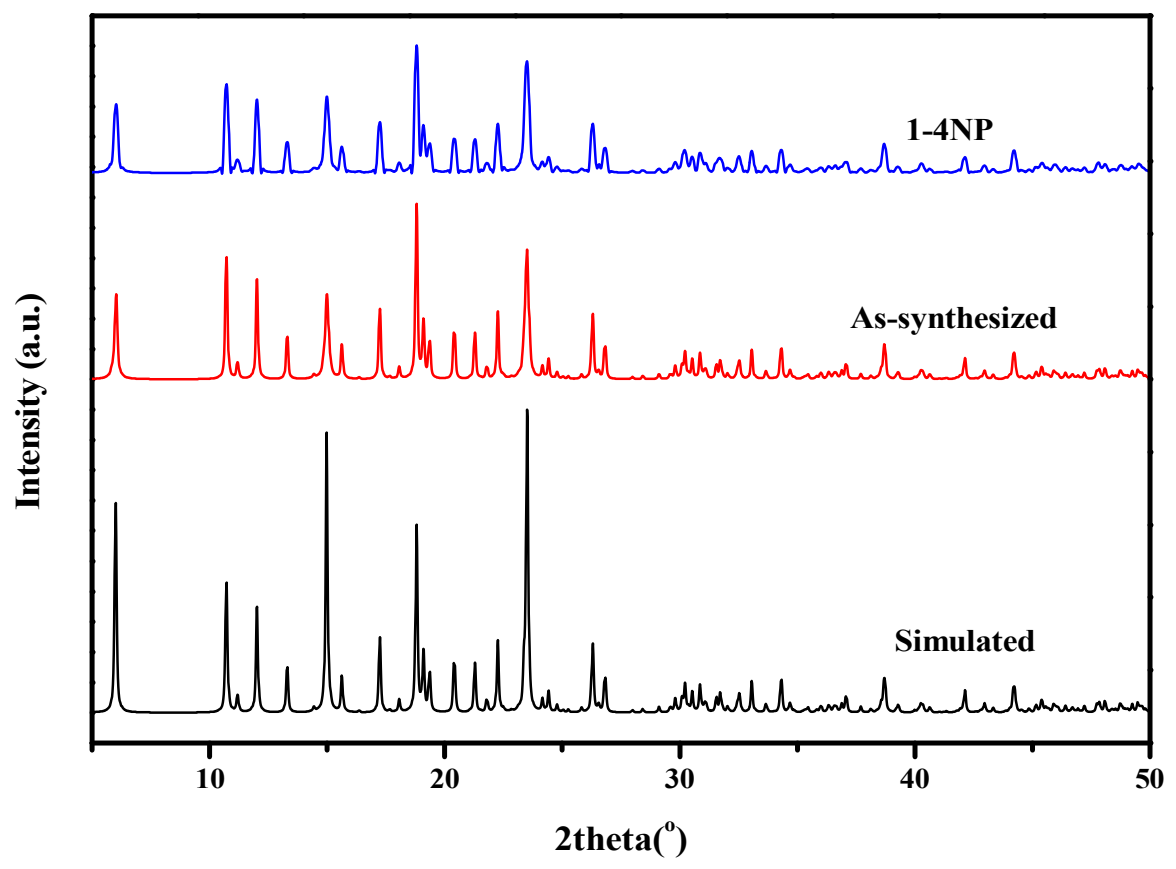

Fig. 6a: PXRD patterns of 1 before and after immersion in 4-nitrophenol 


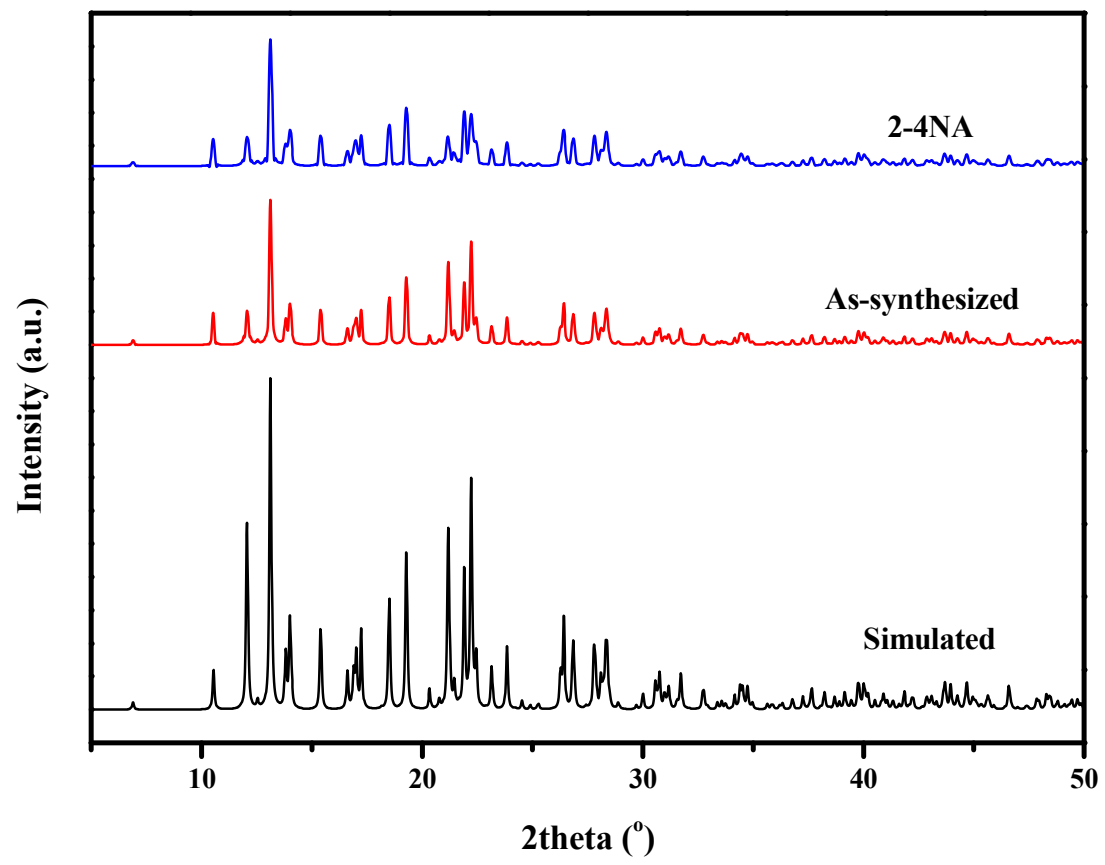

Fig. 6b: PXRD patterns of 2 before and after immersion in 4-nitroaniline

$\mathbf{2}$ was found to perform better than $\mathbf{1}$ in the sensing of the nitro analytes studied, having higher quenching percent towards the nitroaromatic compounds (Fig. 6c). The mechanism of the sensing and superiority of $\mathbf{2}$ over $\mathbf{1}$ was further investigated by DFT studies. 


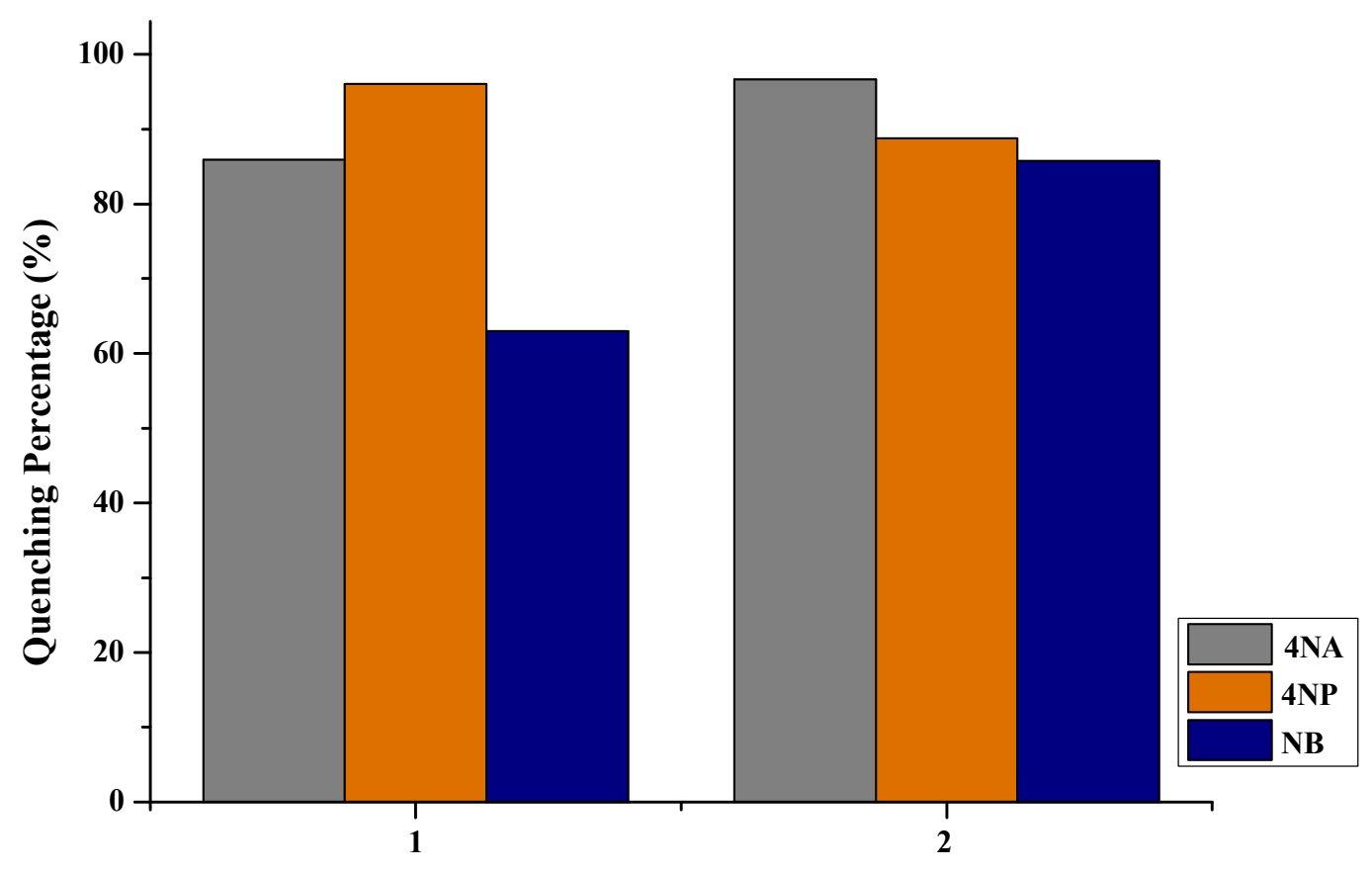

Fig. 6c: Quenching capacity of the compounds in the different nitro analytes

\subsection{Recyclability}

The recyclability of the compounds in the nitro-analytes (4-NP and 4-NA) was investigated by washing in DMF several times. The intensities of $\mathbf{1}$ and $\mathbf{2}$ did not change significantly after three-fold use (Fig. 6d \& 6e). 


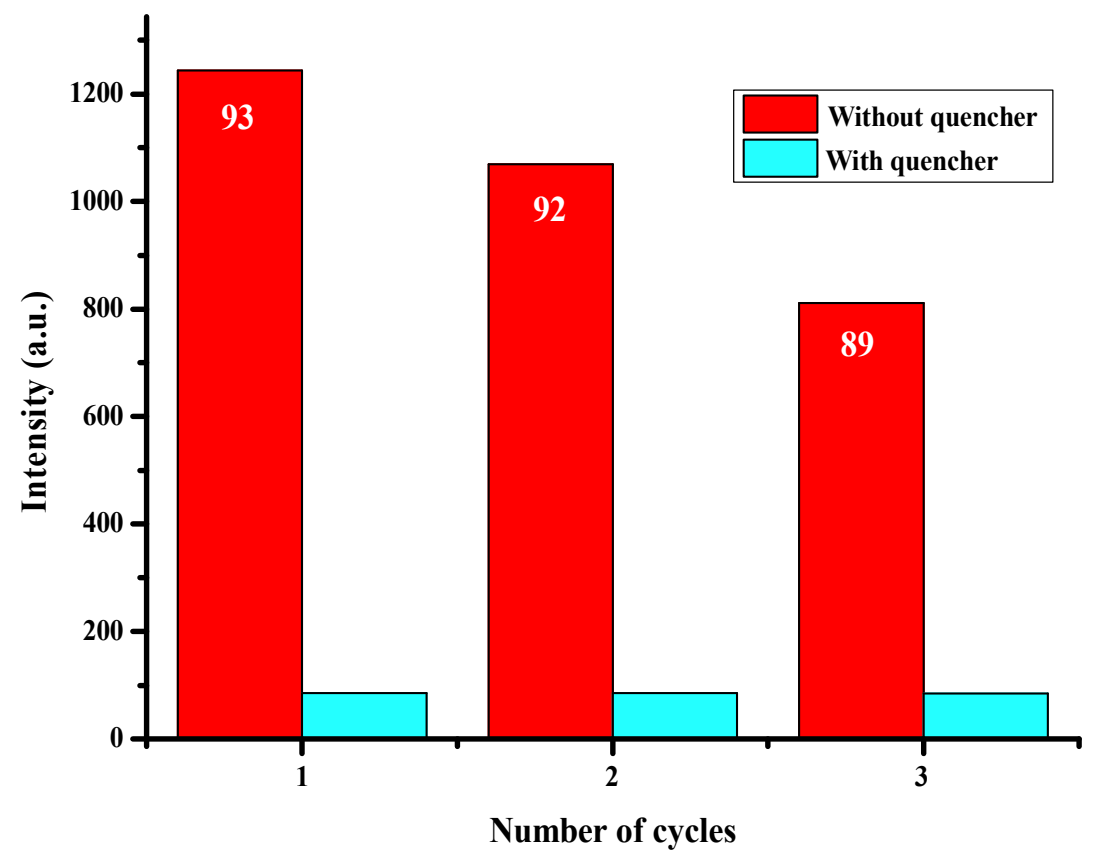

Fig. 6d: Changes in emission intensities of 1 after three recycles in 1mM 4-NP

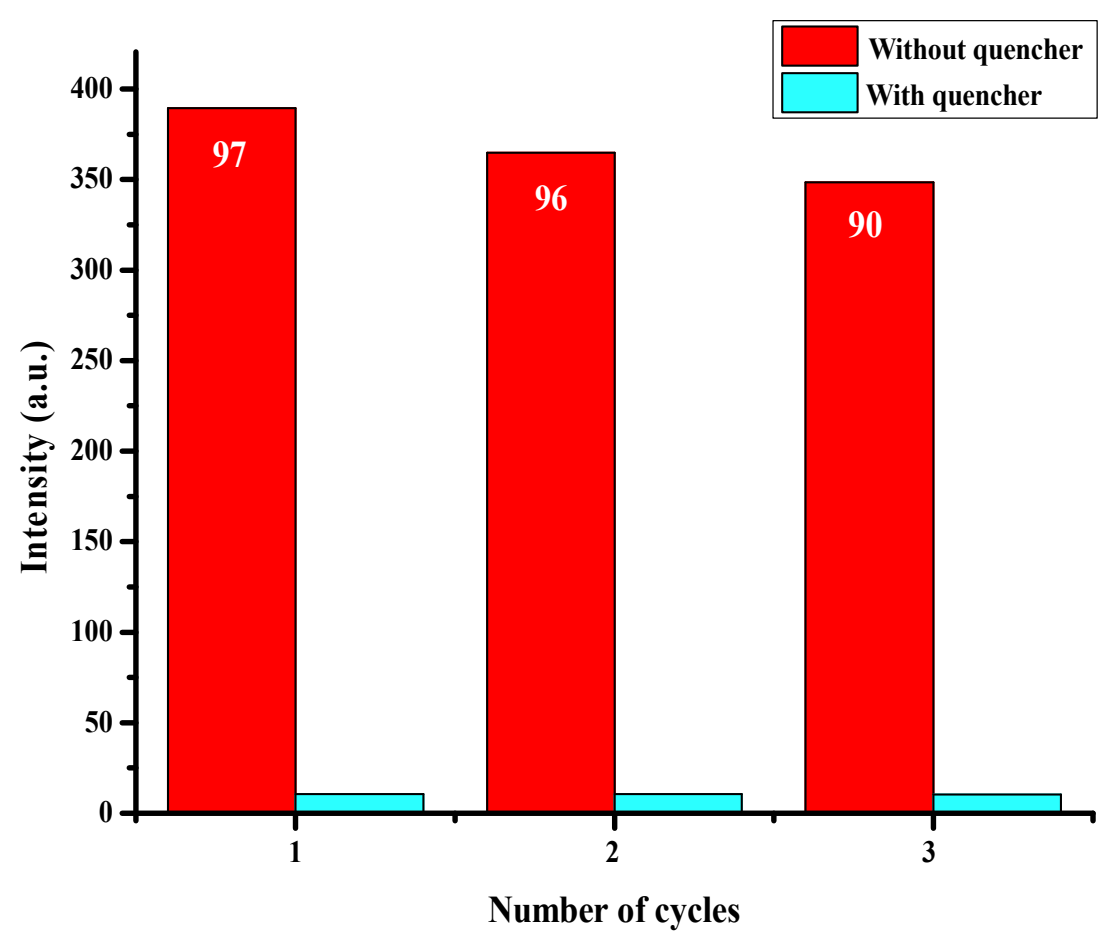

Fig. 6e: Changes in emission intensities of $\mathbf{2}$ after three recycles in 1mM 4-NA 


\subsection{Comparison with other organic solvents}

To confirm the selectivity of $\mathbf{1}$ and $\mathbf{2}$ towards nitroaromatic analytes, the compounds were used to probe other organic solvents. The fluorescence responses of $\mathbf{1}$ and $\mathbf{2}$ to various organics show significant quenching by nitroaromatics including nitrobenzene (NB), 4-nitrophenol (4NP) and 4-nitroaniline (4NA) compared to other organics including alcohols (methanol, ethanol), aromatic (benzene), amine (aniline) and amide ( $N, N$-dimethylformamide) whose effect on the emission of $\mathbf{1}$ and $\mathbf{2}$ is negligible under the same experimental condition (Fig. S9 and S10). The high selectivity was further validated by the fluorescence responses of $\mathbf{1}$ and $\mathbf{2}$ towards 4nitrophenol (4NP) and 4-nitroaniline (4NA) respectively. Moreover, competition experiments of $\mathbf{1}$ and $\mathbf{2}$ in a mixture containing nitroaromatics indicated that luminescent intensities of nitro analytes were unaffected by the presence of other interfering organic solvents (Fig. S9a-c and Fig. S10a-c).

\subsection{Density Functional Theory (DFT) studies}

\subsubsection{Geometry optimization}

The optimized structures of the compounds (CPs) are shown in Fig. S11 and S12, respectively. The optimized structures are similar to that obtained in the experiment. Full optimization of $\mathbf{1}$ and 2 led to the final structure bond lengths and angles slightly different from the experimental (Table 1b). Some slightly overestimated and underestimated calculated bond distances and angles between $\mathrm{Cu}$ and $\mathrm{Co}$ with surrounding atoms are due to movement of electronic density within the compounds.

Frontier molecular orbitals help with predicting reactivity, stability, and resistance of molecules by forecasting their electrical transport properties. HOMO has the ability to donate electrons, while LUMO withdraws electrons [36]. For 1, HOMO originates (Fig. S13a) from the aromatic ring of biphenyl-4-carboxylic acid, while carboxylic groups, copper atom and imidazoyl ring 
contributed to LUMO energies (Fig. S13b). For 2, the metal ion contributes to the HOMO energies (Fig. S14a), while carboxylic groups and imidazoyl ring contributes to the LUMO energies (Fig. S14b). The HOMO-LUMO gap are in the order of $\mathbf{2}(7.036 \mathrm{eV})>\mathbf{1}(8.390 \mathrm{eV})$. Generally, 2 provide a much higher electrical transport properties compared to $\mathbf{1}$. Table 1e, presents the HOMO, LUMO and Band Gap of $\left[\mathrm{Cu}\left(\right.\right.$ Biphen)(Meim) $\left.\left(\mathrm{H}_{2} \mathrm{O}\right)\right]$ and $\left[\mathrm{Co}(\mathrm{BDC})(\mathrm{Meim})_{2}\right]_{\mathrm{n}}$.

\subsubsection{CP-nitro analyte interactions}

Orbital Energy Gap

Wide HOMO-LUMO gap implies high stability, charging resistance, and changes in the number and distribution of electrons. Hence hard molecules have a significant HOMO-LUMO gap. Meanwhile, small HOMO-LUMO gap is indicative of highly polarizable soft molecules, as they need only small amounts of energy to get them to the excited states.

HOMO-LUMO gap

Looking at the three nitro-compounds, 4-nitroaniline and 4-nitrophenol showed a small HOMO-LUMO energy gap which results in better polarization and reactivity as observed in the fluorescence studies. Conversely, when compared with 4-nitrophenol and 4-nitroaniline, nitrobenzene provided the largest HOMO-LUMO energy gap indicating a hard molecule with low reactivity (Table 1e).The HOMO-LUMO gap energies of nitro compounds are in the order: Nitrobenzene $(4.679 \mathrm{eV})>$ Nitrophenol $(4.558 \mathrm{eV})>$ Nitroaniline $(3.763 \mathrm{eV})$ (Table 1e).

Adducts formed between 1 and nitro compounds suggested that HOMO was derived from nitro compounds and 1 (around Biphen) while LUMO was derived from 1 (Fig. 7). This obviously confirmed that the interaction between the $\mathbf{1}$ and the nitro compounds is through the HOMO donation of electrons to the LUMO [37]. Therefore, potential interactions resulting from adduct 
formation are mediated by the hydrogen bonding between (4-nitrophenol and 4-nitroaniline) and the $\pi$ face of 1 [38].

Nitro compounds showed that the HOMO and LUMO centers on 2, resulting in an interaction ( $\pi-\pi$ stacking) between the 2 and the Nitro compounds (nitrobenzene, 4-nitrophenol, 4nitroaniline) (Fig. 8). However, the calculated LUMO energies for the molecules of the nitro analytes lie lower than that of $\mathbf{1}$ and $\mathbf{2}$ which means that excited electrons can be transferred from the conduction band of the frameworks to the LUMOs of the nitro analytes (Fig. 9) [39].

LUMO energies with lower energy values are more important in evaluating favourable interaction between compounds (CPs) and nitro-molecules, because the LUMO sites contribute to the overlapping of incoming HOMO orbitals. The energy gaps of adducts formed between 1 with Nitrobenzene, Nitrophenol and Nitroaniline are 9.196, 9.138 and $9.016 \mathrm{eV}$, respectively, while 2 with nitrobenzene, nitrophenol and nitroaniline are $7.099,7.125$ and $6.936 \mathrm{eV}$, respectively. Based on the reported LUMO energy values of adducts, 4-nitroaniline is the most favourable molecule for the quenching of $\mathbf{2}$ while the LUMO energy values of $\mathbf{1}$ adducts do not adhere to the experimental order of decrease in photoluminescent intensity, which indicates that charge transfer may not be the only phenomenon responsible for quenching [40].

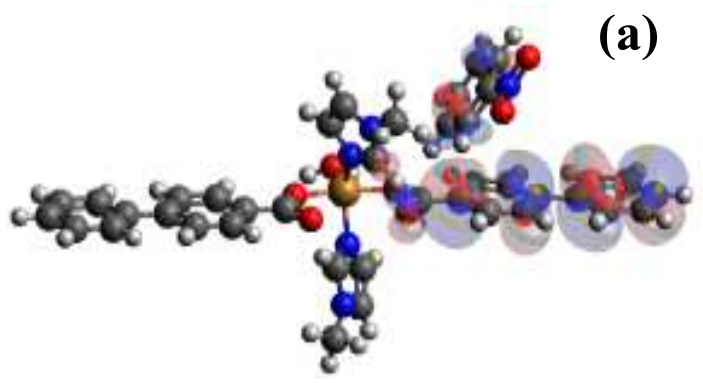

(c)

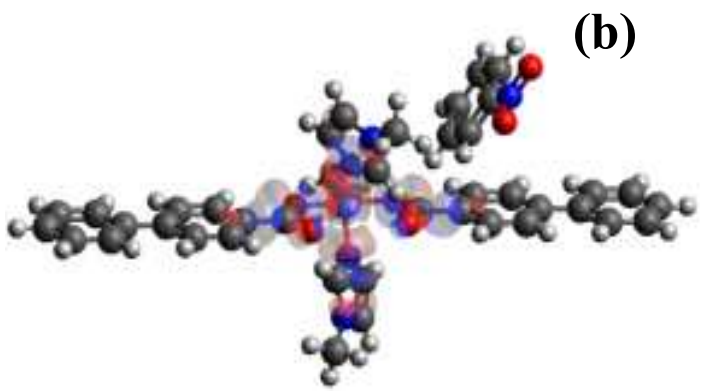

(d)

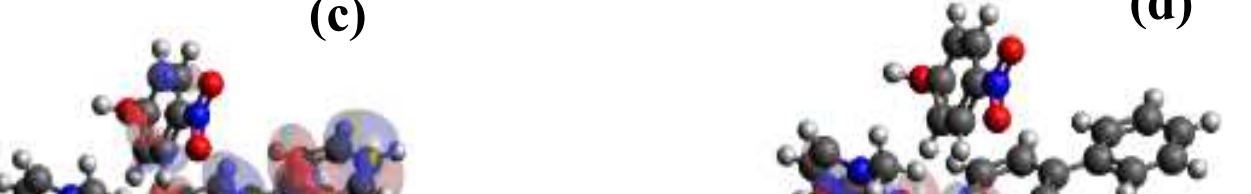


Fig. 7: Frontier orbitals showing (a) HOMO and (b) LUMO positions of 1-nitrobenzene, (c) HOMO and (d) LUMO positions of 1-nitrophenol and (e) HOMO and (f) LUMO positions of 1-nitroaniline.
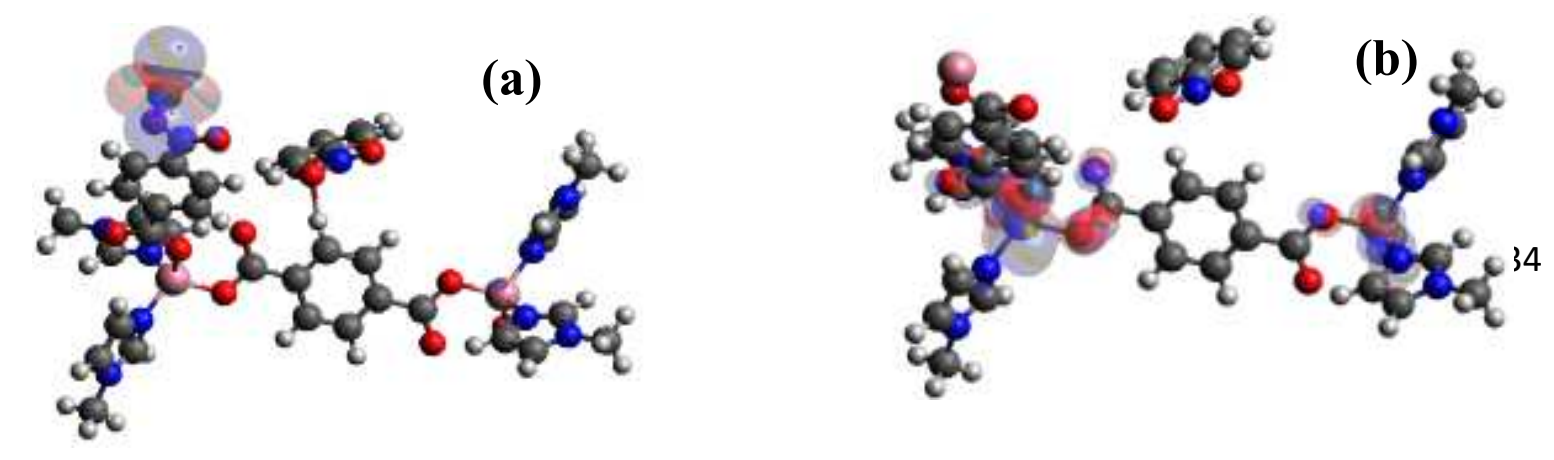

(d) 
Fig. 8: Frontier orbitals showing (a) HOMO and (b) LUMO positions of 2-nitrobenzene, (c) HOMO and (d) LUMO positions of 2-nitrophenol and (e) HOMO and (f) LUMO positions of 2-nitroaniline. 


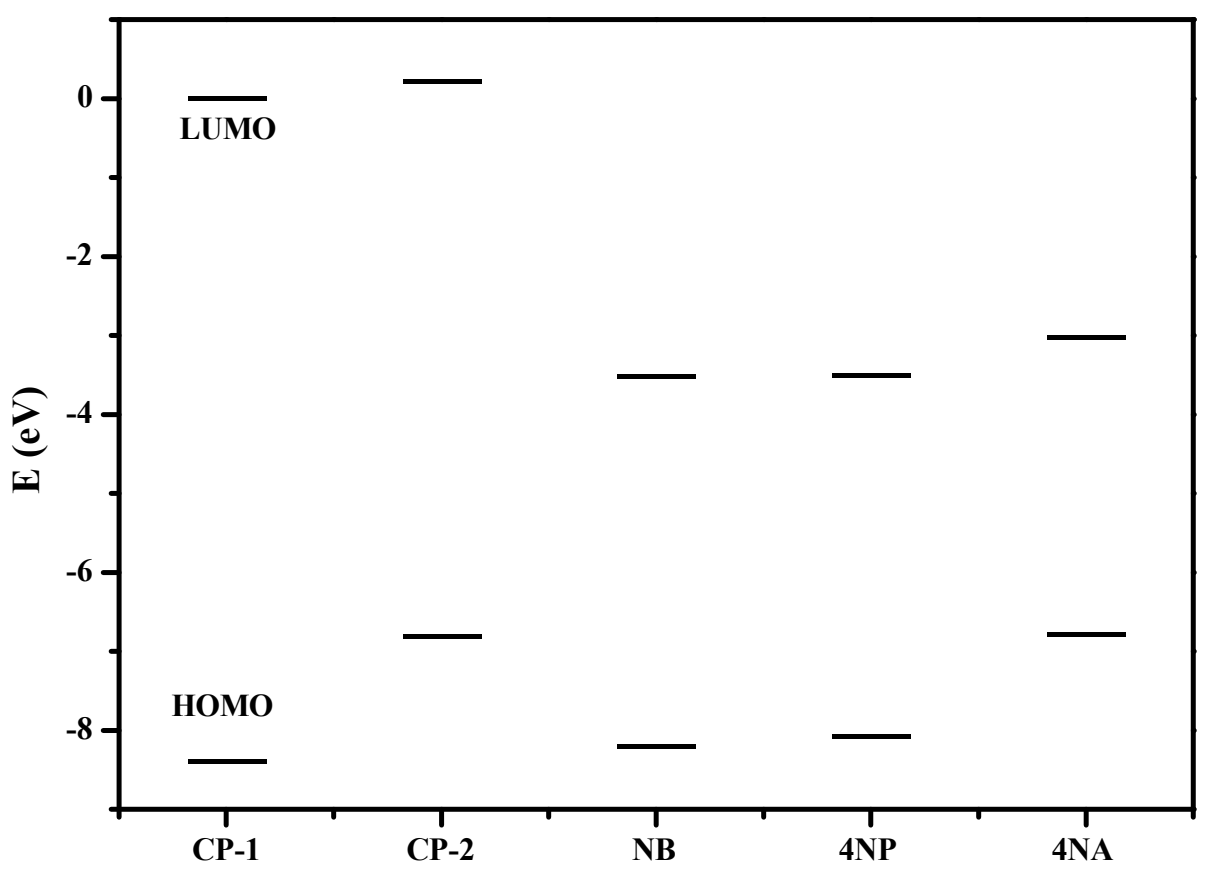

Fig. 9: HOMO-LUMO energy profiles of compounds and nitro analytes

Table 1e: HOMO, LUMO and Band Gap of 1, 2, CPs-nitroanalytes and nitroaromatic molecules

\begin{tabular}{|l|l|l|l|}
\hline & HOMO $(\mathbf{e V})$ & LUMO $(\mathbf{e V})$ & Band Gap (eV) \\
\hline $\mathbf{1}$ & -8.281 & 0.109 & 8.390 \\
\hline $\mathbf{2}$ & -6.700 & 0.336 & 7.036 \\
\hline 1-nitrobenzene & -8.425 & 0.771 & 9.196 \\
\hline 1-nitrophenol & -8.381 & 0.757 & 9.138 \\
\hline 1-nitroaniline & -8.373 & 0.643 & 9.016 \\
\hline 2-nitrobenzene & -6.287 & 0.812 & 7.099 \\
\hline 2- nitrophenol & -6.308 & 0.817 & 7.125 \\
\hline 2- nitroaniline & -6.465 & 0.47 & 6.936 \\
\hline Nitrobenzene & -8.080 & -3.401 & 4.679 \\
\hline Nitrophenol & -7.957 & -3.399 & 4.558 \\
\hline Nitroaniline & -6.668 & -2.905 & 3.763 \\
\hline
\end{tabular}


Preliminary theoretical studies was conducted to compare the energy gap of the 4-nitrophenol adducts when metal centers are swapped ( $\mathrm{Co}$ for $\mathrm{Cu}$ in $\mathbf{1}$ and $\mathrm{Cu}$ for $\mathrm{Co}$ in $\mathbf{2}$ ). This resulted in a slight increase in energy band gaps (Table 1f), hence, lowering the quenching ability. The optimized structure and HOMO-LUMO position for the interaction of 4-nitrophenol with swapped metal center is reported in the supplementary data section (Figures S15-S16). From the theoretical studies, it is obvious that band gaps of synthesized compounds $\mathbf{1}$ and $\mathbf{2}$ play significant role in influencing quenching ability.

Table 1f: HOMO, LUMO and Band Gaps of swapped metal centers

\begin{tabular}{|l|l|l|l|l|l|l|}
\hline & \multicolumn{3}{|c|}{ Current Study } & \multicolumn{3}{l|}{$\begin{array}{l}\text { Metal center swapped (Co for Cu in 1 } \\
\text { and Cu for Co in 2) }\end{array}$} \\
\hline & $\begin{array}{l}\text { HOMO } \\
(\mathrm{eV})\end{array}$ & $\begin{array}{l}\text { LUMO } \\
(\mathrm{eV})\end{array}$ & $\begin{array}{l}\text { Band } \\
\text { Gap }(\mathrm{eV})\end{array}$ & $\begin{array}{l}\text { HOMO } \\
(\mathrm{eV})\end{array}$ & $\begin{array}{l}\text { LUMO } \\
(\mathrm{eV})\end{array}$ & $\begin{array}{l}\text { Band Gap } \\
(\mathrm{eV})\end{array}$ \\
\hline $\begin{array}{l}\text { 1-nitrophenol } \\
\text { 2- } \\
\text { nitrophenol }\end{array}$ & $\mathbf{- 8 . 3 8 1}$ & $\mathbf{0 . 7 5 7}$ & $\mathbf{9 . 1 3 8}$ & -8.307 & $\mathbf{0 . 7 3 2}$ & $\mathbf{9 . 0 3 9}$ \\
\hline
\end{tabular}

\section{Conclusions}

Two new coordination compounds were successfully synthesized using flexible carboxylate and imidazoyl ligands. The compounds show excellent luminescent response by virtue of their photophysical properties. The luminescence intensities of the $\mathbf{1}$ and $\mathbf{2}$ were found to be quenched drastically by nitroaromatic analytes and upon incremental concentrations of the nitro analytes. 2 was found to have superior sensitivity towards the nitro analytes compared to 1. All experimental results indicate that the selectivity of the CPs relates to both the structures and electronic properties of the CPs and the nitro-analytes, as well as to the essence of their interactions. Computational studies have also shown that interactions between the structures and the nitro analytes could result from strong intermolecular hydrogen bonding, $\pi$ - $\pi$ stackings 
and photo-induced electron transfer. The fast response time, sensitivity and recyclability make them potential materials for commercial grade sensors.

\section{Conflict of Interest}

There are no conflicts to declare.

\section{Supplementary data}

CCDC 2016804 and 1999492 contains the crystallographic data of [Cu(Biphen)(Meim)( $\left.\left.\mathrm{H}_{2} \mathrm{O}\right)\right]$ 1 and $\left[\mathrm{Co}(\mathrm{BDC})(\mathrm{Meim})_{2}\right]_{\mathrm{n}} \mathbf{2}$, respectively. These data can be obtained free of charge from the Cambridge Crystallographic Data Centre via www.ccdc.cam.ac.uk/structures

\section{Acknowledgements}

We are grateful to Royal Society of Chemistry (RSC) for funding and also to the School of Chemistry, University of Nottingham for X-ray crystallography analysis of the compounds. The authors thank Redeemer's University, Ede, Nigeria for the fluorescence studies and the Center for High Performance Computng (CHPC), Capetown, South Africa for providing the platform to carry out molecular modelling studies using the Gaussian09 software.

\section{References}

1. S.R. Batten, N. R. Champness, X-M. Chen, G-M. Javier, S. Kitagawa, L. Ohrstrom, M. O’Keeffe, M. K. Suh, J. Reedijk

CrystEngComm, 14 (2012) p. 3001-3004.

2. D. T. McQuade, A. E. Pullen, T. M. Swager

Chem. Rev. 100 (2000) p. 2537-2574.

3. D. S. Moore

Rev. Sci. Instrum. 75 (2004) p. 2499-2512. 
4. Y.W. Li, J.R Li, L.F. Wang, B.Y. Zhou, Q. Chen, X.H. Bu,

J. Mater. Chem. A 1 (2013) p. 495-499.

5. A.A. Tehrani, L. Esrafifili, S. Abedi, A, Morsali, L. Carlucci, D.M. Proserpio, J. Wang, P.C. Junk, T.F. Liu

Inorg. Chem. 56 (2017) p. 1446-1454.

6. D. Tian, Y. Li, R.Y. Chen, Z. Chang, G-Y Wang, X-H Bu

J. Mater Chem A 2 (2014) p. 1465-1470.

7. A-L. Li, Y-H. Qu, L. Fu, C. Han, G-H. Cui

CrystEngComm, 22 (2020) p. 2656-2666.

8. $\quad$ Y-J. Yang, Y-H Li, D. Liu, G-H. Cui

CrystEngComm, 22 (2020) p. 1166-1175.

9. A.C. Tella, M.D. Olawale, M. Neuburger, J.A. Obaleye

Journal of Solid-State Chemistry 255 (2017) p. 157-166.

10. A.C. Tella, A.C. Oladipo, V.O. Adimula, O.A. Ameen, S.A. Bourne, A.S. Ogunlaja, New Journal of Chemistry 43 (2019) p.14343-14354.

11. A.C. Tella, S.O. Owalude, M.F. Omotoso, S.J. Olatunji, A.S. Ogunlaja, L.O. Alimi, O.K. Popoola, S.A. Bourne Journal of Molecular Structure 157 (2018) p. 450 - 455.

12. A.C. Tella, G. Mehlana, L.O. Alimi, S.A. Bourne

Zeitschrift fur anorganishe und allgemeine chemie (ZAAC) 64 (2017) p. 523-530.

13. G-Y. Wang, L-L. Yang, L. Yue, H. Song, W-J. Ruan, Z. Chang, X-H. Bu Dalton Trans 42 (2013) p.12865-12868.

14. M. J. Frisch, G. W. Trucks, H. B. Schlegel, G. E. Scuseria, M. A. Robb, J. R. Cheeseman, G. Scalmani, V. Barone, B. Mennucci, G. A. Petersson, H. Nakatsuji, M. Caricato, X. Li, H. P. Hratchian, A. F. Izmaylov, J. Bloino, G. Zheng, J. L. Sonnenberg, M. Hada, M. Ehara, K. Toyota, R. Fukuda, J. Hasegawa, M. Ishida, T. Nakajima, Y. Honda, O. Kitao, H. 
Nakai, T. Vreven, J. A. Montgomery Jr, J. E. Peralta, F. Ogliaro, M. Bearpark, J. Heyd, E. Brothers, K.N. Kudin, V.N. Staroverov, R. Kobayashi, J. Normand, K. Raghavachari, A. Rendell, J. C. Burant, S. S. Iyengar, J. Tomasi, M. Cossi, N. Rega, J. M. Millam, M. Klene, J. E. Knox, J. B. Cross, V. Bakken, C. Adamo, J. Jaramillo, R. Gomperts, R.E. Stratmann, O. Yazyev, A. J. Austin, R. Cammi, C. Pomelli, J. W. Ochterski, R. L. Martin, K. Morokuma, V. G. Zakrzewski, G. A. Voth, P. Salvador, J. J. Dannenberg, S. Dapprich, A. D. Daniels, Ö. Farkas, J. B. Foresman, J.V. Ortiz, J. Cioslowski, D. J. Fox, (2016), GAUSSIAN 16, Revision D.01, Gaussian Inc., Wallingford, CT.

15. A. D. Becke

J. Chem. Phys, 98 (1993) p. 5648-5652.

16. C. Lee, W. Yang, R.G. Parr Phys. Rev. B, 37 (1988) p. 785-789.

17. O. V. Dolomanov, L. J. Bourhis, R. J. Gildea, J. A. K Howard, H. Puschmann

J. Appl. Cryst. 42 (2009) p. 339-341.

18. G. M. Sheldrick

Acta Cryst. A71 (2015) p. 3-8.

19. G. M. Sheldrick

Acta Cryst C71 (2015) p. 3-8.

20. A. W. Addison, T. N. Rao, J. Reedijk, J. Van Rijn, G. C. Verschoor

J. Chem. Soc., 7 (1984) p. 1349-1356.

21. K. Das, S. Dolai, P. Vojtisek, S.C. Manna

Polyhedron 149 (2018) p. 7-16.

22. A.C. Tella, S.O. Owalude, S.J. Olatunji, S.O. Oloyede, A.S. Ogunlaja, S.A. Bourne J Sulfur Chem 39 (2018) p. 588-606.

23. D.F. Shriver, P.W. Atkins

Inorganic chemistry $3^{\text {rd }}$ edn (1999) p. 235-236. 
24. Z-X. Li, X. Chu, G-H. Cui, Y. Liu, L. Li, G-L. Xue

CrystEngComm 13 (2011) p. 1984-1989.

25. H. Zhou, G.X. Liu, X.F. Wang, Y. Wang

CrystEngComm 15 (2013) p. 1377-1388.

26. S. S. Prasad, M.R. Sudarsanakumar, V.S. Dhanya, S. Suma, Prathapachandra Kurup M.R.

Journal of Molecular Structure 1173 (2018) p. 196-204.

27. N. Hojnik, M. Kristl, A. Golobic `` Z. Jaglic `ic', M. Drofenik

Central Eur J Chem 12 (2014) p. 320-6.

28. S. M. Sheta, M. E. Said, M. M. Abd-Elzaher

Dalton Trans., 47 (2018) p. 4847-4855.

29. R. A. Ahmadi, F. Hasanvand, G. Bruno, H. A Rudbari, S. Amani

Inorganic Chemistry (2013) p. 1-7.

30. G.Y. Wang, C. Song, D.M. Kong, W.J. Ruan, Z. Chang, Y. Li J.

Mater. Chem. A 2 (2014) p. 2213-2220.

31. L.H. Cao, H.Y. Li, S.Q. Zang, H.W. Hou, T.C.W. Mak

Cryst. Growth Des. 12 (2012) p. 4299-4301.

32. G. F. Ji, J. J. Liu, X. C. Gao, W. Sun, J. Z. Wang, S. L. Zhao, Z. L. Liu

J. Mater. Chem. A 5 (2017) 10200.

33. S. Pramanik, C. Zheng, X. Zhang, T. J. Emge, J. Li

J. Am. Chem. Soc 133 (2011) p. 4153-4155.

34. H. Sohn, M. J. Sailor, D. Magde, W. C. Trogler

J. Am. Chem. Soc 125 (2003) p. 3821-3830.

35. Q. Tu, L. Ren, Y. Cui, A. Cheng, E. Gao

CrystEngComm. (2020) p. 21-24. 
36. Y. Ji1, X. Liu, G. Fu, Y. Chen, F. Wang, J. Zhao

Materials Science and Engineering 87 (2015) p. 012104

37. J.H. Qin, H.R. Wang, M.L. Han, X.H. Chang, L.F. Ma

Dalton Trans 46 (2017) p. 15434-15442.

38. S. Kumar, N. Venkatramaiah, S. Patil

J. Phys. Chem. C, 117 (2013) p. 7236-7245.

39. L. Liu, X. Chen, J. Qiu, C. Hao

Dalton Trans., 44 (2015) p. 2897-2906.

40. J. Wang, J. Wu, L. Lu, H. Xu, M. Trivedi, A. Kumar, J. Liu, M, Zheng Front. Chem. 7 (2019) p. 244. 